\title{
DESIGN AND THE ISLAMIC ENVIRONMENT IN A CHANGING WORLD STUDY OF THE EXPERIENCES OF THE ARAB TOWNS ORGANIZATION AND THE AGA KHAN ARCHITECTURE
}

\section{Emad Abdel-Rahman Hammad}

Assistant Professor, Department of Decor (Interior Architecture), Faculty of Fine Arts - Alexandria University

(Received January 4, 2010 Accepted April 1, 2010).

One of the most important principles of an architectural and design thinking at the beginning of the twentieth century is a separation from the past and making use of scientific progress and technology. If this principle had reported progress in the design of his time, and despite the positive aspects of this thought, this technological progress is clear, we find the negatives lead to what we now call the dilemma of technology that is threatening pollution in many ways which are relevant to our lives in general and the special design. So it was an urgent call to address this shift in the spatial and visual environment to raise cultural and artistic awareness, and urging designers to produce work of a contemporary design and eco-friendly through the use of appropriate building materials to the environment, And interest in gardening, landscaping and distribution of plants and the safe design of buildings, and the philosophy of the use of color and control systems in the internal environment through lighting, sound and air-conditioning and methods of water supply and sanitation, In addition to taking into account the prevailing wind direction for private residential buildings in addition to consensus building with customs and traditions and character of the city and the link to the environment.. To fit in line with our environment and our beliefs and the law of environmental and cultural tradition with contemporary methods and techniques.

When the Arab cities lost their cultural identity and physical personality as a result of the invasion of Western cultural and intellectual trends and colorful design between tradition and contemporary We dealt with those intellectual trends through the content of Islamic thought, Questionnaire to the ability of these trends in the formulation of that content in a modern framework to preserve the cultural inheritance, rather than increase the penetration of Western cultures in our societies, As well as the ability of the designer in the contemporary formulation of that content in the context of modern processions of modern technology. The research was based on four basic objectives:

- Monitoring of design experience in different environments and different eras verify their compatibility with the environment.

- Sustainable environment and the Islamic concept as a method based upon regulatory hubs building design work. 
- The link between interior design and architecture makes it a social means of communication which plays a main role in shaping the environment visual arts and cultural community.

- Highlighting the philosophical and environmental dimensions of the Prizes of the Arab Towns Organization and the Aga Khan Architecture.

The research follows historical and analytical approach in monitoring some of the different architectural models with an explanation of the characteristics, The search follows the descriptive approach in his presentation of the trends between the different intellectual tradition and contemporary design to achieve the substance of Islamic thought in the context of a modern and in several points can be summarized as follows:

1. Concept of Environment

1/1 Sustainable Environment \& Islamic Concept

1/2 The Influence of Environment on Design

2. Contemporary Design Thought

2/l Environmental Pollution\& Inner Space

$2 / 2$ Pollution of The Optical Environment

2/3 Effective Elements in Optical Environment

3. The concepts of sustainability and green buildings

4. Design \& Islamic Environment

5. Experiences of the Arab Towns Organization and the Aga Khan Architecture

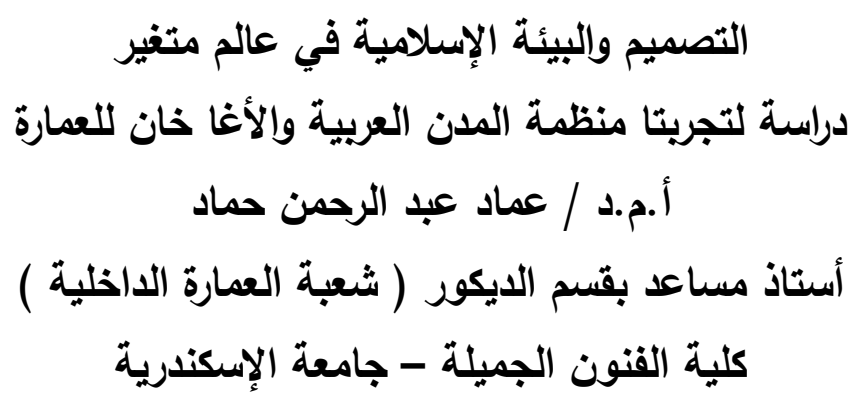

يجمع التصميم بين الحقائق المادية وبين المشاعر الوجدانية أي بين منطق البناء ومنطق الحياة لكل

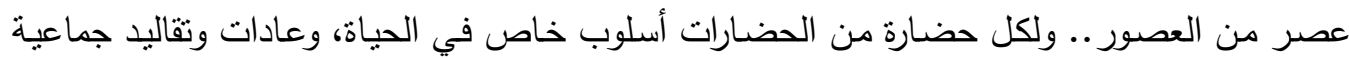
تكونت نتيجة للظروف والمؤثرات، فجعلت لهذا العصر أو للحضـارة صفات، وأعطت لعمارته شكلاً

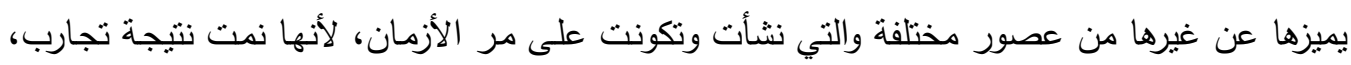

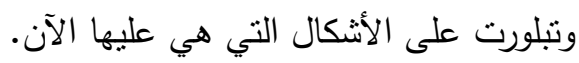
والتصميم كفن هندسي لابد وان يتوافق مع العقيدة والمستلزمات والروابط الاجتماعية والضوابط الثرعية الثية

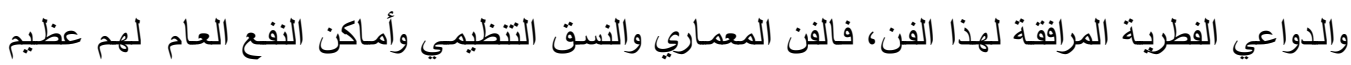


الأثر في بنـاء العلاقات الإنسانية ومتانـة النسيج الاجتماعي وإنـاعة النتوحد وتعميق الأصسول النفسية للتكامل الاجتماعي منل التعاون والتراحم وحسن التجاور والإحسان وما إلى ذلك تللك المعاني التي تبناها الفكر الإسلامي منذ نشأته في عمرانه في حين اختقت وماتت هذه المعاني في عمران المدينة الحديثة ذات التوجه الغربي.

المقدمة : 2 - 2

إن العمران البشري بالمفهوم العقلي يشمل النشاط الإنساني في كافة المجالات المادية والفكرية والثقافية

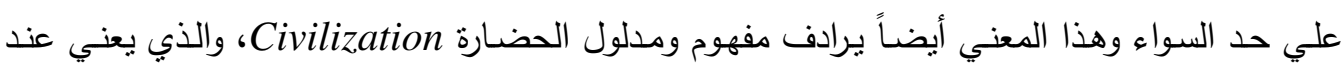

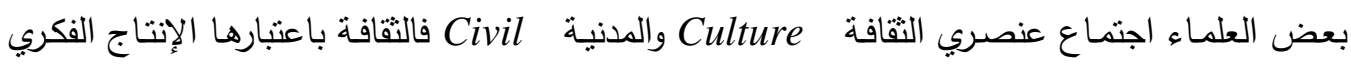

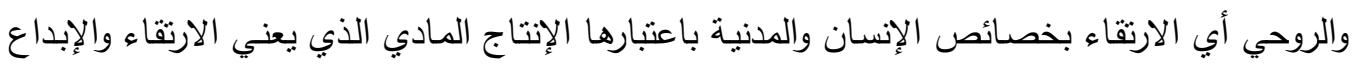
تعنإ:Creation تعني عالم الأثياء وبذلك تكون الحضارة هي العمران بشكل عام. وأصبح تجسيد الرموز الثقافية هدفا ضمن الأهداف الرئيسية التي تسعى لتحقيقها أي أمة من أجل أبلى إبراز

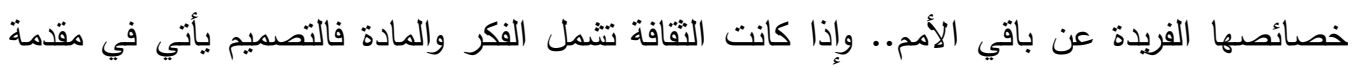
المعالم التقافية والمادية التي تحمل قدرة على تجسيد قضايا فكرية واجتماعية مهمة ممثلة في الثنكل

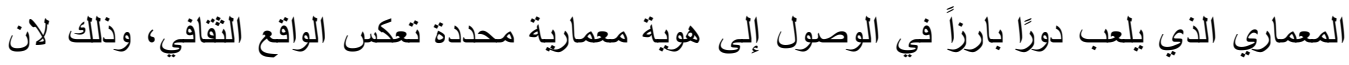

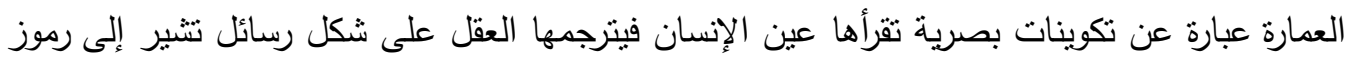

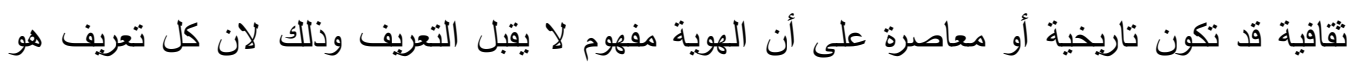

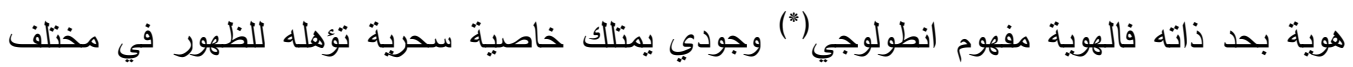
المقولات المعرفية وهو يتمتع بدرجة عالية من العمومية والتجريد تفوق كل المفاهيم الأخرى المتجانسة والمقابلة له فالعمارة الإسلامية ليست ككل الطرز الأمر الذي يجعلنا نثير حولها الكثير من الأسئلة

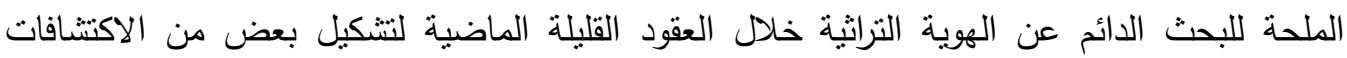
المهمة حول ثقافتتا .

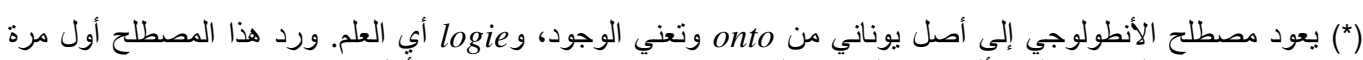

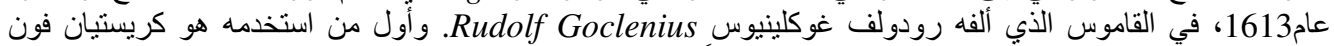

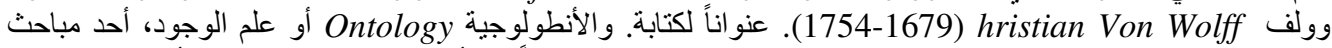

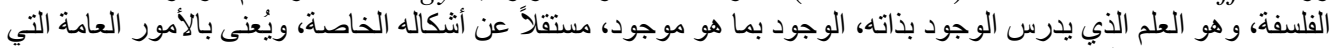

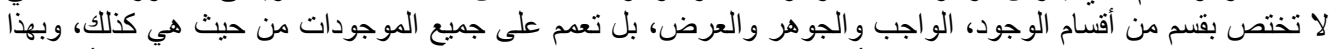

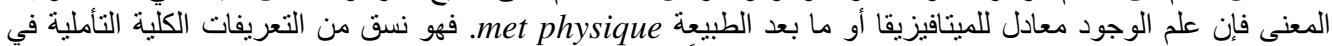

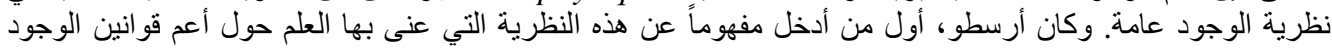
http://www.arab-ency.com/index.php?module=pnEncyclopedia\&func= للمزيد راجع

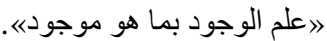
display_term\&id=1256 
وظلت العمارة في نهضة وتطور مواكبة للمتغيرات الوظيفية والبيئية على مر العصور المتلاحقة، وعندما بدأ الزحف التقافي الغربي يتغلغل في مدننا، تارة بفرض الوصاية وتارة أخري بالاستعمار ، مها كان له له

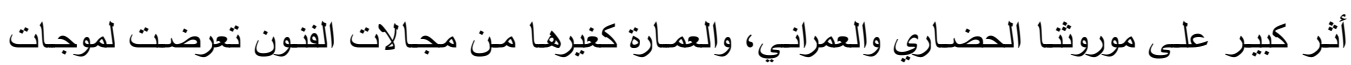

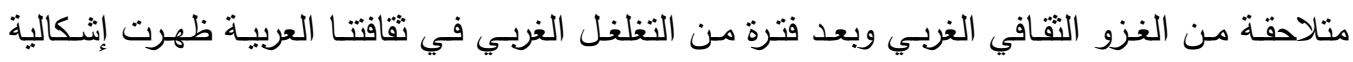

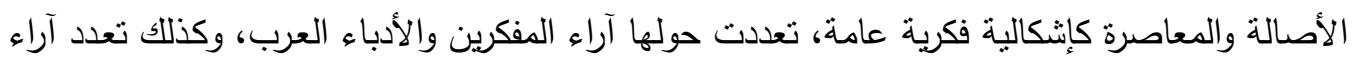
المعماريين واتجاهاتهم بين مؤيد ومعارض ومتحفظ بينهما، فكثر النقاش والجدل حول مفهوم الأصالة

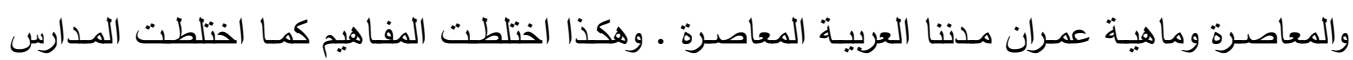

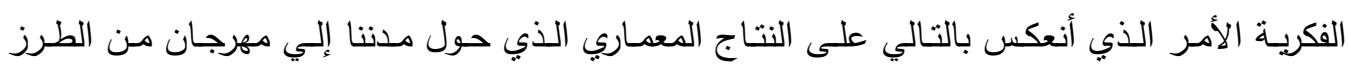

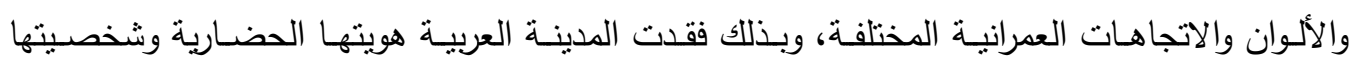

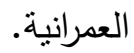

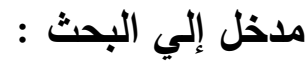

كانت إحدى أهم المبادئ التي نأسس عليها الفكر المعماري والتصميمي في بداية القرن العشرين هي

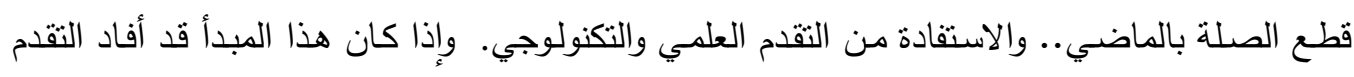

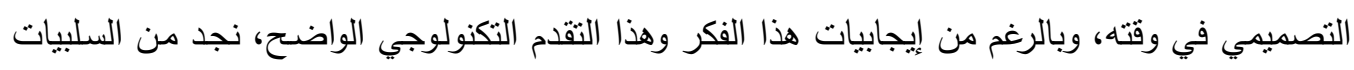

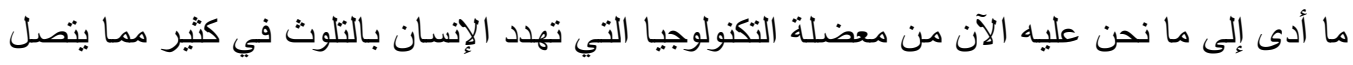

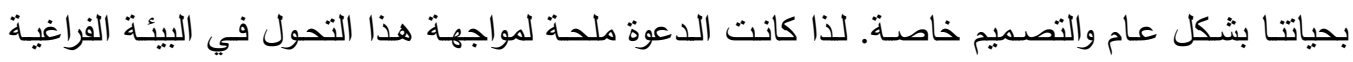
والبصرية نحو إيقاظ الوعي الثقافي والفني، وحث المصممين على إنتاج أعمال تصميمية معاصـرة

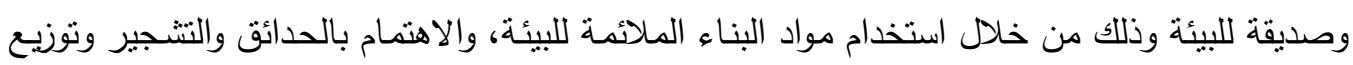
النباتات والتصميم الآمن للمباني، وفلسفة استخدام الألوان ونظم التحكم في البيئة الداخلية من خلادل

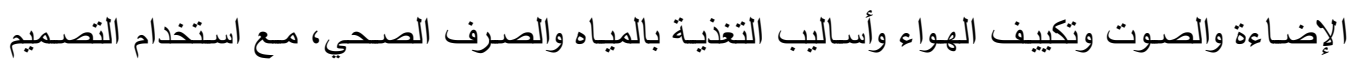

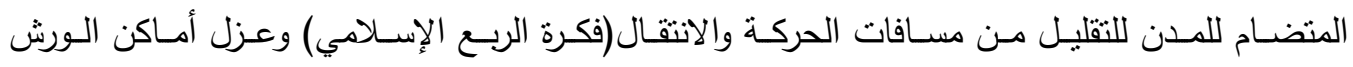

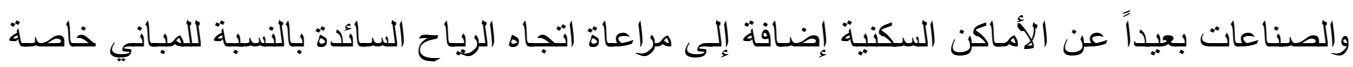

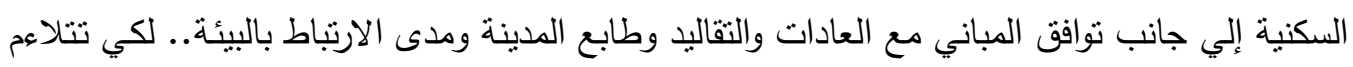

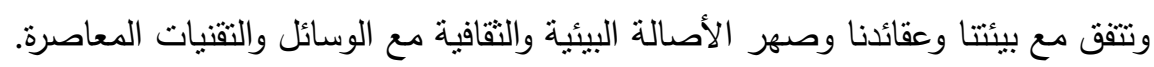

\section{هدف البحث :}

لما فقدت المدينـة العربيـة هويتها الحضارية وشخصيتها العمرانية نتيجة للغزو التقافي الغربي وتعددت

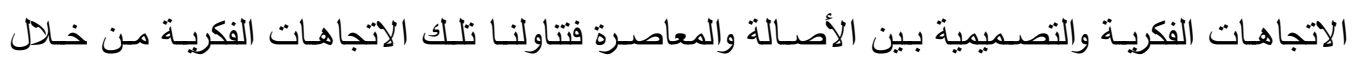
مضمون الفكر الإسـلامي لاستبيان مدي قدرة تلك الاتجاهـات في صباغة ذلك المضمون في إطـار 
عصري للحفاظ على المبراث الحضاري بدلا من زيادة تغلغل النقافات الغربية في مجتمعاتتا. وكذلك قدرة المصمم المعاصر في صياغة ذلك المضمون في إطار عصري مواكب للنكنولوجيا الحديثة. وقد أرتكز

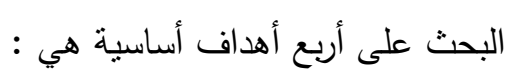

• رصد التجربة التصميمية في بيئات متتوعة وعصور مختلفة تحقق فيها التوافق مع البيئة.

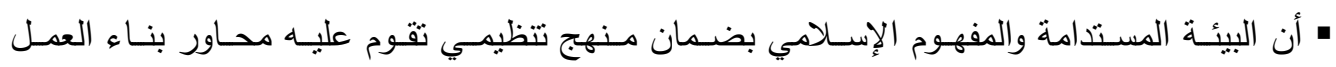
التصميمي.

• أن ارتباط التصميم الداخلي بالعمارة يجعله وسيلة اتصـال اجتماعية تلعب دوراً أساسياً في تتكيل البيئة البصرية الفنية والنقافية للمجتمع. • إلقاء الضوء على الأبعاد الفلسفية والبيئية لجائزتي منظمة المدن العربية والأغا خان للعمارة. منهزج البحث: يتخذ البحث المنهج التحليلي التاريخي وذلك في رصد بعض النماذج المعماريـة المختلفة مـع شرح لخصائصها. كما يتبع البحث المنهج الوصفي في عرضـه للاتجاهات الفكرية المختلفة بين الأصـالة والمعاصرة في التصميم لتحقيق مضمون الفكر الإسلامي في إطار عصري وذلك في عدة نقاط نوجزها في الآتي:

\section{Concept of Environment مفهوم البيئة}

Sustainable Environment \& Islamic Concept 1/1 البيئة المستدامة والمفهوم الإسلامي

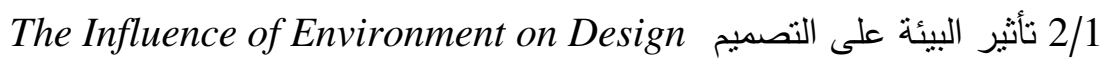

Contemporary Design Thought الفكر التصميمي المعاصر

Environmental Pollution\& Inner Space النلوث البيئي والفراغ الداخلي 1/2 Pollution of The Optical Environment نلوث البيئة البصرية 2/2/2 3/2 العناصر المؤثرة في الثلوث البصري Effective Elements in Optical Environment 3- مفاهيم الاستدامة والعمارة الخضراء: Design \& Islamic Environment التصميم والبيئة الإسلامية والعمارة 5- تجريتا منظمة المدن العربية والأغا خان للعمارة:

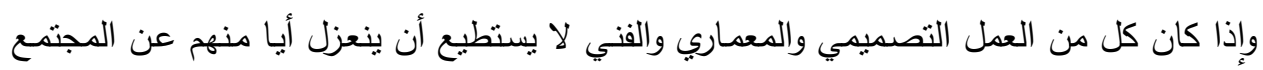

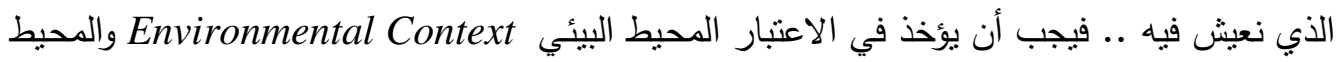
البصر optical Context عند الممارسة التصميمية .. التي تحوي اللغة .. والأسلوب والنظرية . 


\section{Concept of Environment 1 مفهوم البيئة}

البيئة في اللغة العربية .. يعود إلى ( بوأ ) والفعل ( باء) وتبوء أي نزل وأقام.. والبيئة والمباءه بمعنى

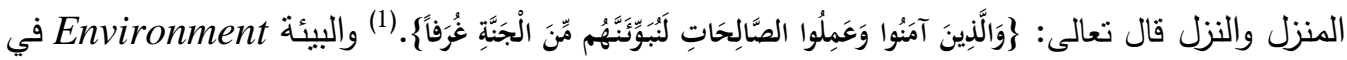
المعاجم الإنجليزية .. تعني مجموعة الظروف والمؤثرات الخارجية التي لها تأثير في حياة الإنسان والكائنات. (2) أما علم البيئة الحديث Ecology فيعرف بأنه الوسط أو المجال المكاني الذي يعيش فيه الإنسان.(") وهناك تخصصات في علوم البيئة منل البيئة الوراثية ولاجتماعية والثقافية والمناخية والحضرية والبحرية والبشرية..إلخ.( 1) وبالنسبة للتصميم بشموله العام المعماري والفني نستطيع إيجاز مفهوم عملية التصميم في أنها عملية إيجاد بيئة متوازنة من خلال روية تشكيلية عضوية تجمع بين البيئات الثلاث:(البيئة الطبيعية ،البيئة المصنوعة، البيئة الإنسانية )."*(")

Sustainable Environment \& Islamic Concept البيئة المستدامة والمفهوم الإسلامي 1/1 يتميز الإسلام برؤية عميقة وشاملة للبيئة (4) حيث لم تقتصر نظرة الإسلام للبيئة على البعد المكاني فقط

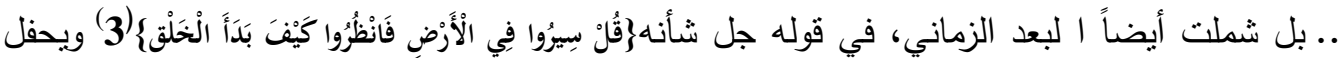

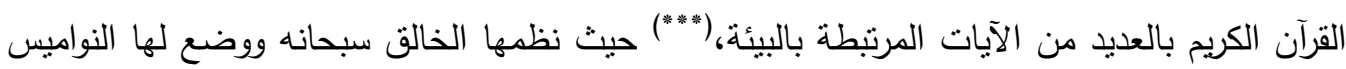
التي تكفل حفظ التوازن البيأي مصداقاً لقوله \} إِنَّا كُلَّ شَيْءٍ خَلَقْنَاهُ بِقَدَرِ \{ (5) فكل شيء خلق بمقدار له دور Sustainable محد ومرسوم بدقة وتوافق وانسجام وحكمة تؤكد مفهوم البيئة المستدامة Environment بعداً زمنياً هاماً في التعامل مع النظام البيئي Environmental System ("***"*ن منطلق أنه نعمة

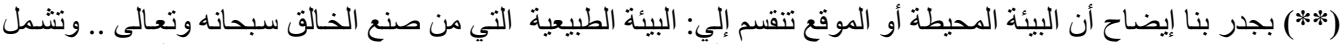

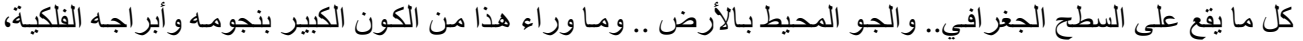

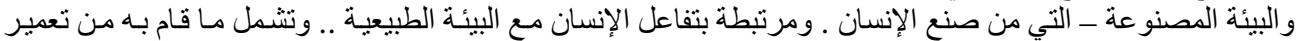

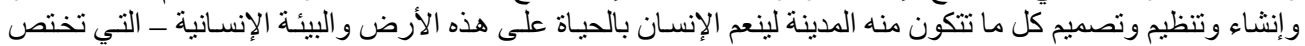
بذاتية الإنسان. (4) محمد عبد القادر ألفقي " البيئة ـ مشاكلها وقضاياها وحمايتها من التلوث " المرجع السابق ، ص. 19، 25 . (5) سورة العنكبوت ، آية رقم 20 (5)

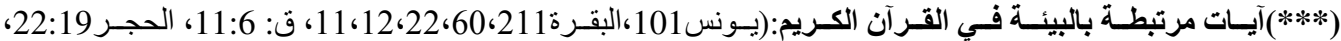

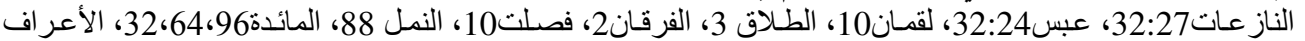

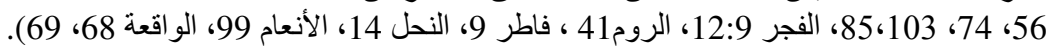
(6) سورة القمر ، آية رقم 9 ؛

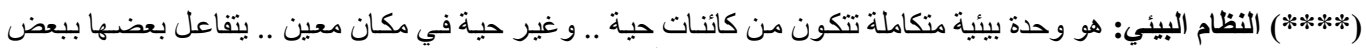
وفق نظام دقيق ومتوازن في ديناميكية ذاتية لتستمر في أداء دور هـا في إعالة الحياة. ويتكون النظام البيئي من: (1) 
كبرى للإنسان ودعانا إلى النظر والتأمل في مكونات البيئة وسائر المخلوقات. وإذا كانت رسالة الإنسان

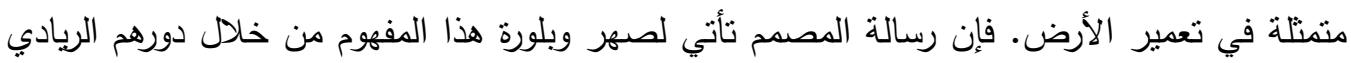
في مختلف جوانب التعمير والبناء والتتكيل.. وتطويع إبداعاتهم التصميمية وملامتها لتتاسب الإنسان وبيئته.

The Influence of Environment on Design أثير البيئة على التصميم 2/1 اختلفت الفنون والعمارة في الحضارات القديمة في كل أمة من الأمم بل وفى كل إقليم عن الآخر تبعاً

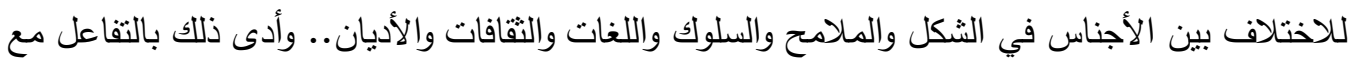

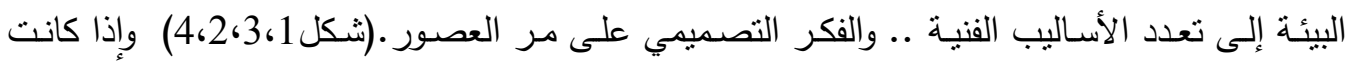

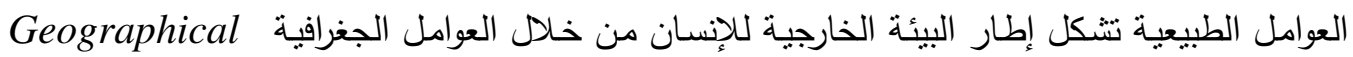
والجيولوجية Geological والمناخية Climatic وهي ذات ظروف متتوعة من مكان لآخر ("**" مما

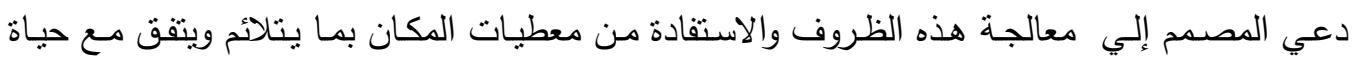
الإنسان. فمثلاً. كان للفن والعمارة في مصر القديمة أصول عضوية في بدايتها عندما كانت أنثكالها

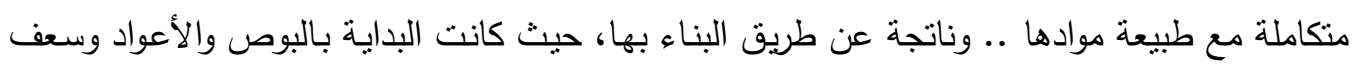

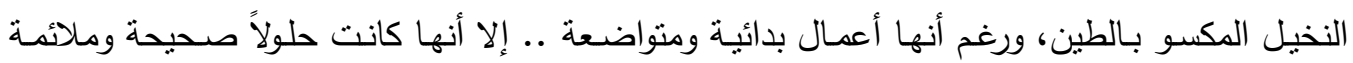
ملاءمه دقيقة لكل ظروفها ومسبباتها ومتوطنة ومتأصلة في بيئتها.

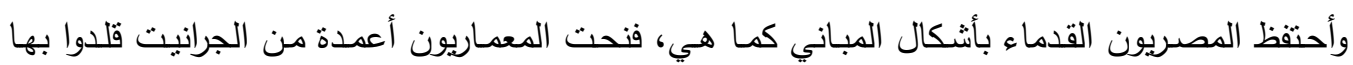

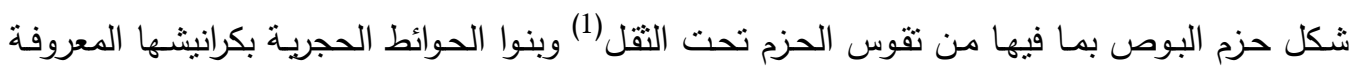

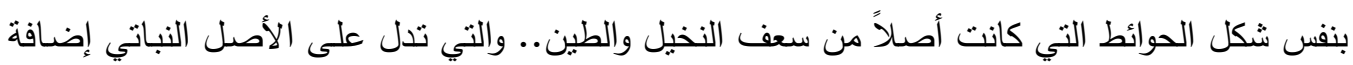

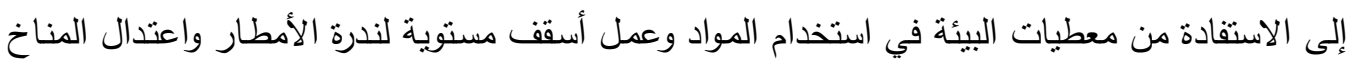
وكذلك نحت المعابد والمقابر في الجبال، وقد ظلت أساليب البناء ثابتة لم تتغير لآلاف السنين.

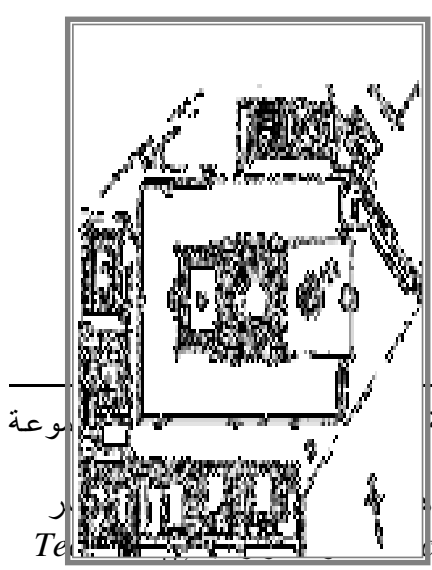

209

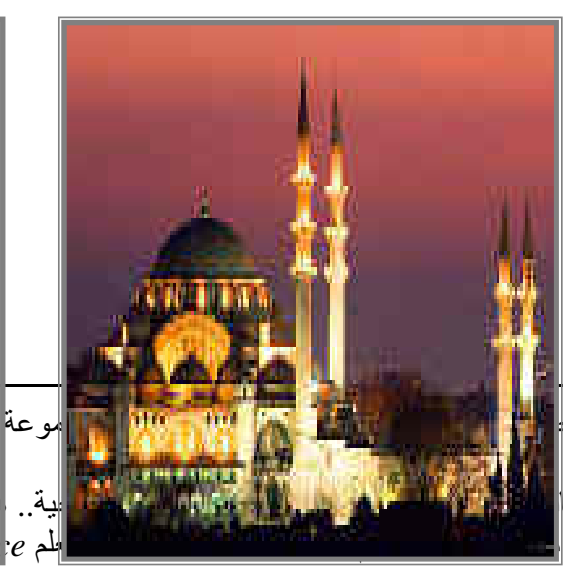

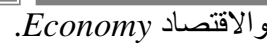

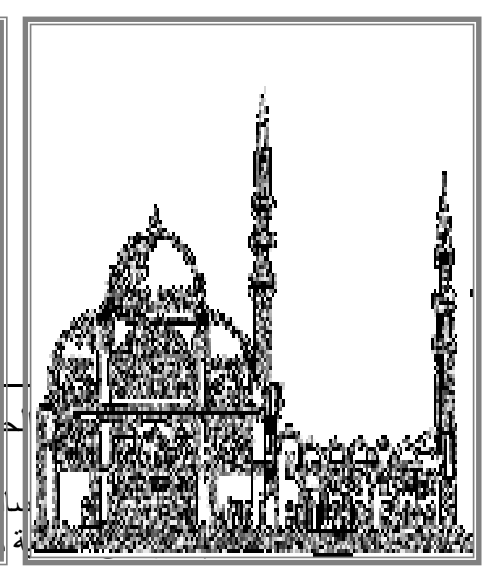

(1) 
( شكل 1) جامع السليمانية - تركيا (*) ويوضح العمارة الإسلامية والقدرة على التأقلم مع البيئة
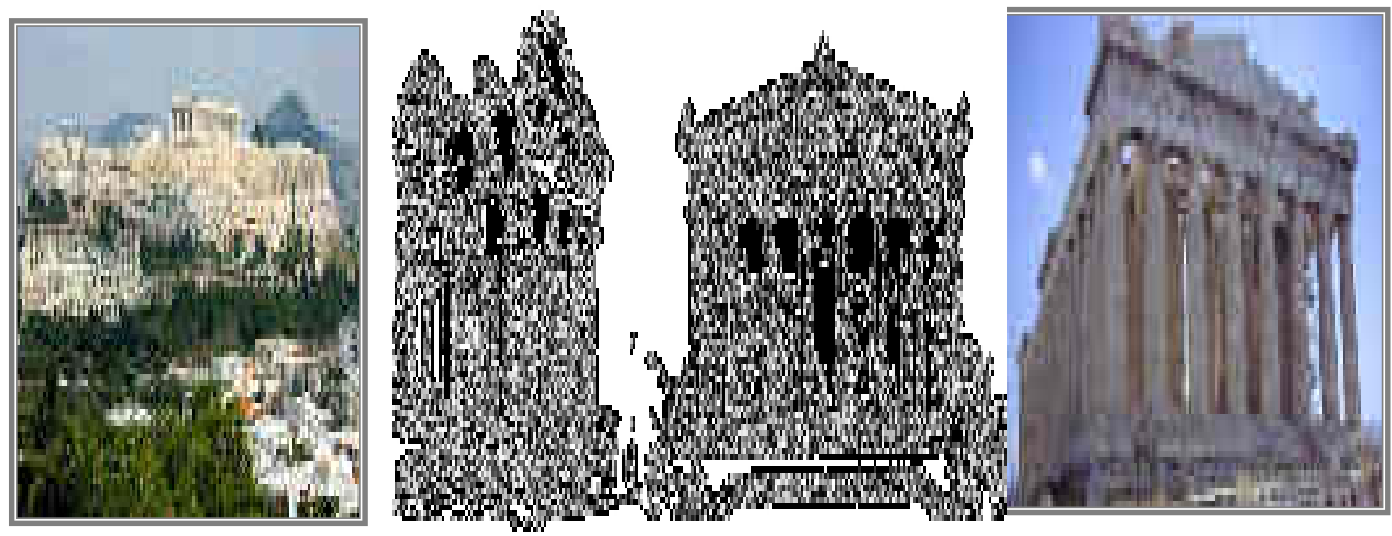

( شكل 2) معبد البارثنون ("*) العمارة الإغريقية - وتأثثر الأرض الجبلية، والبيئة الطبيعية على التصميم
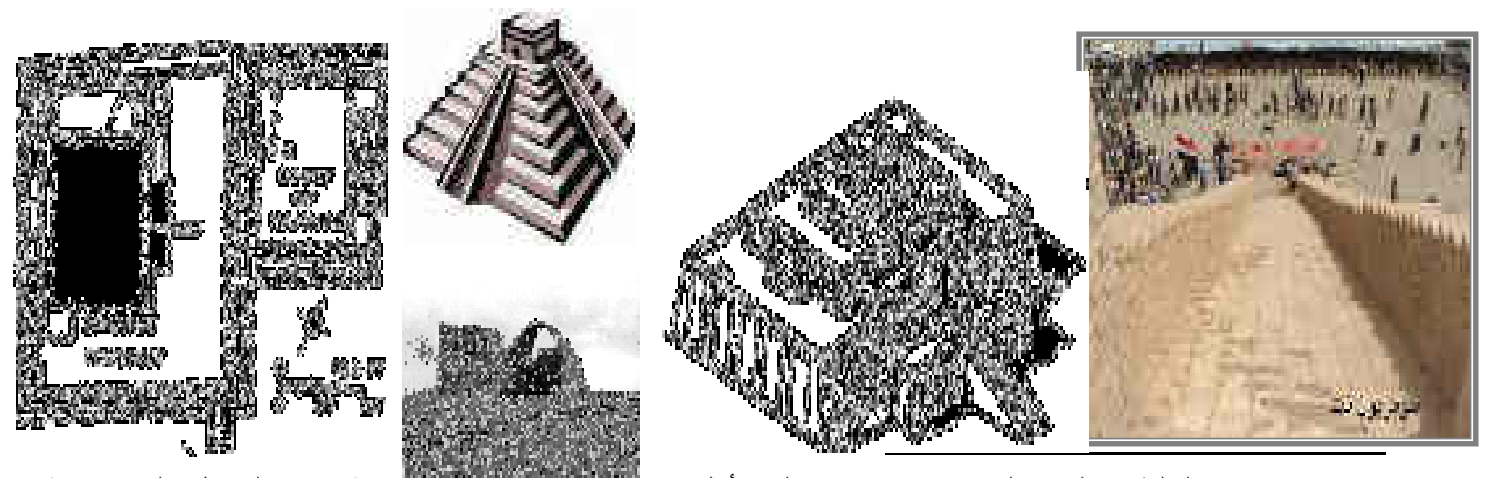

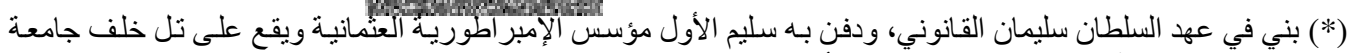

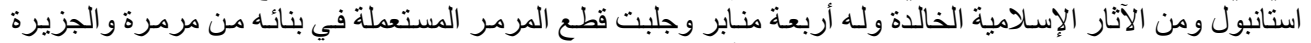

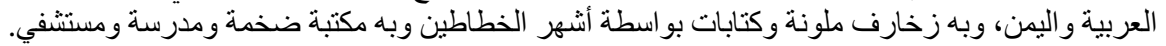

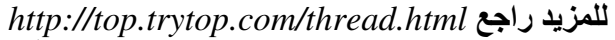

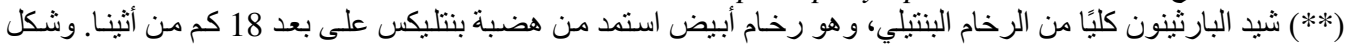

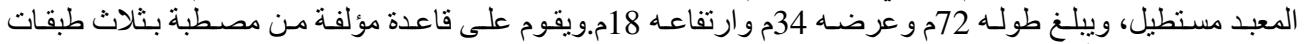

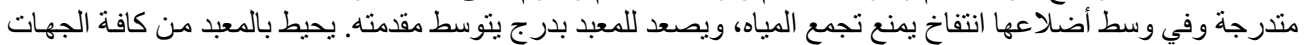

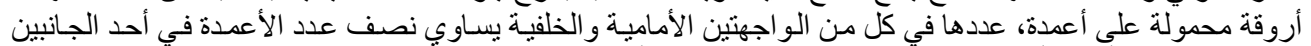

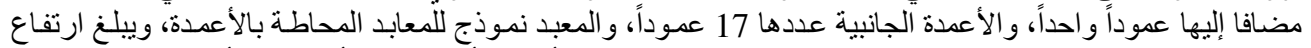

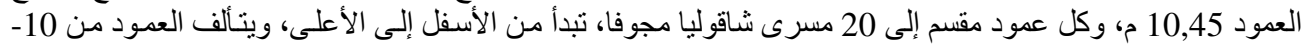

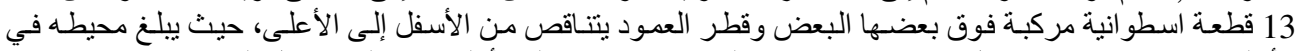

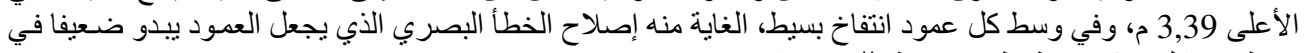

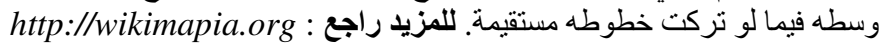


( شكل 3) هدينة أور (**") بلاد ما بين النهرين، وأسلوب تتاول الزيقورات للتظلب على مشاكل السيول والفيضانات
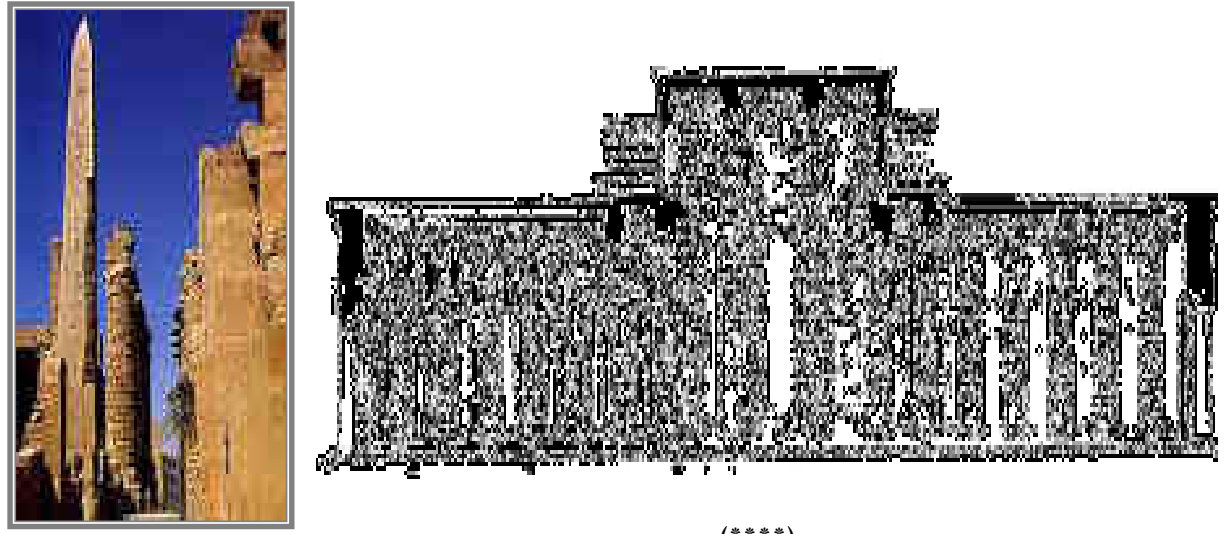

( شكل 4) معبد الكرنك ("***) العمارة المصرية القديمة،

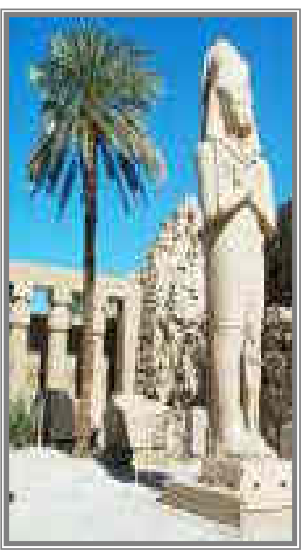

والأصول العضوية، والارتباط بالبيئة النبانية
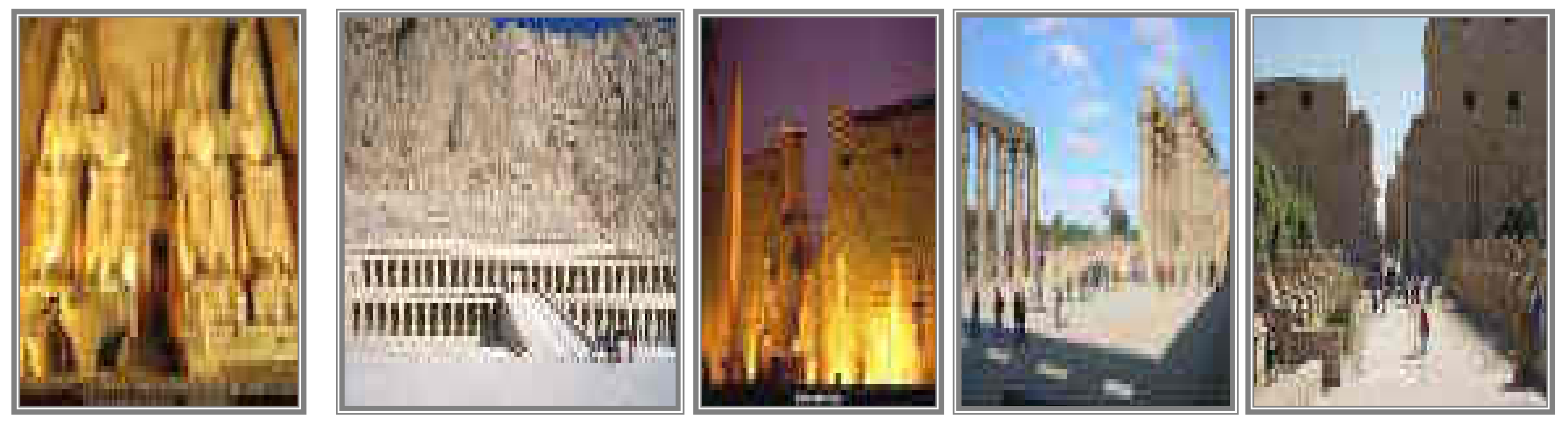

وفي عمارة بلاد ما بين النهرين كان لاجتياح السيول والفيضانات سبباً في دفع المعماري والمصدم لبناء

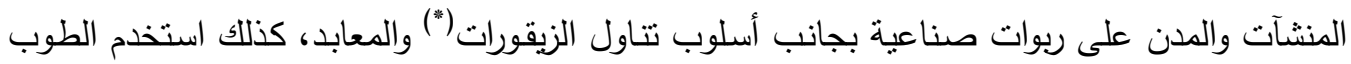

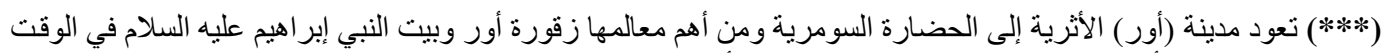

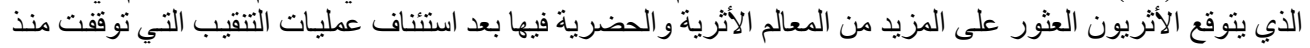

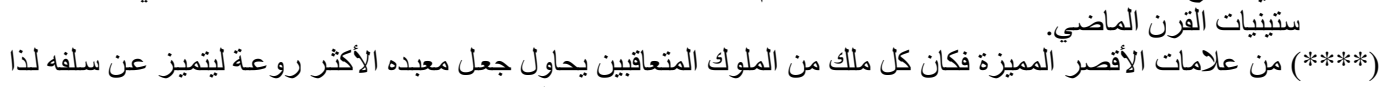

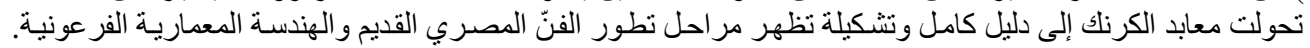

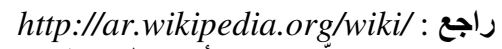

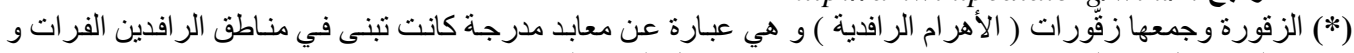

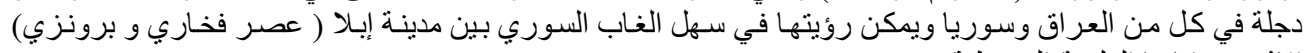


الني والمحروق والمزجج بشكل أساسي في البناء كمادة منوفرة في البيئة واستخدمت الأفنية المكثوفة التي تحيط بها الصالات للمعالجة المناخية بسبب الحرارة والرطوبة .

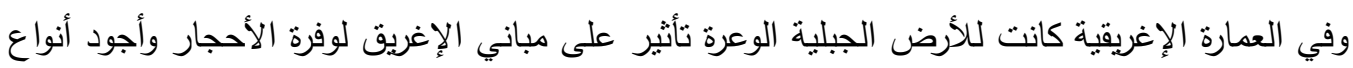

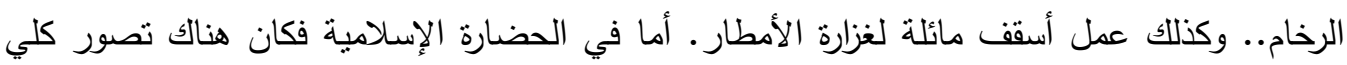

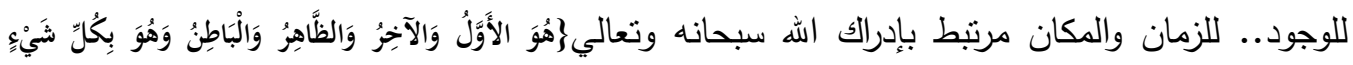

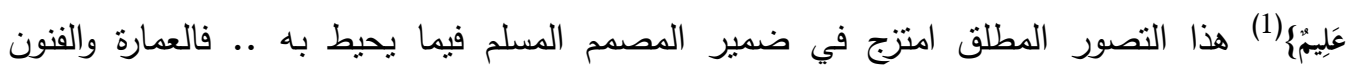

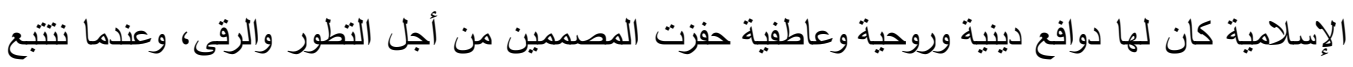

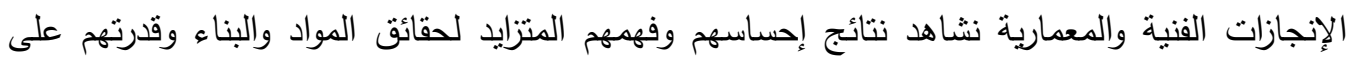
التأقلم("*) لظروف المناطق والبيئات المختلفة في العالم الإسلامي الممتد، ولم تكن الأساليب المعمارية ذات طراز واحد بل اختلفت وتميزت في كل إقليم على مدى العصور المختلفة.

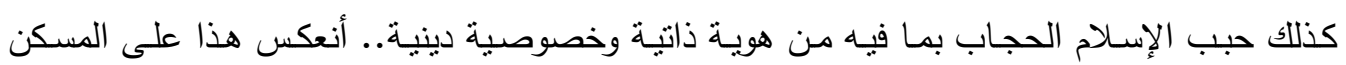
الإسلامي الذي يفتح على الداخل ( الفناء) Court yard فكانت معالجة الفراغ الداخلي بأساليب معمارية وفنية تختلف عن الفراغ الخارجي Outer Space من حيث تحقيق الظل وشبه الظل والخضرة والماء وتحقيق الخصوصية.(* *") هذا إلى جانب مراعاة الظروف المناخية وعوامل البيئة والحياة الاجتماعية

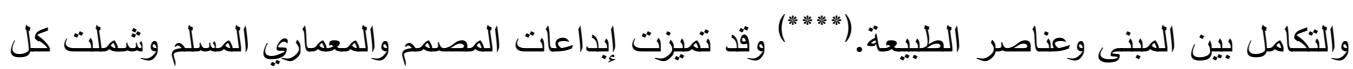

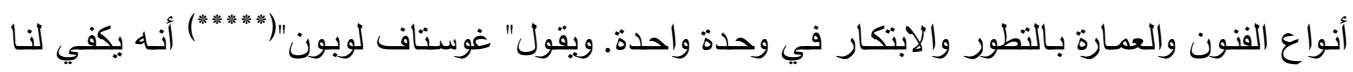

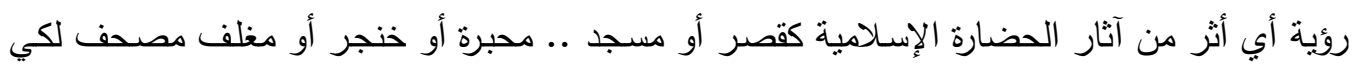

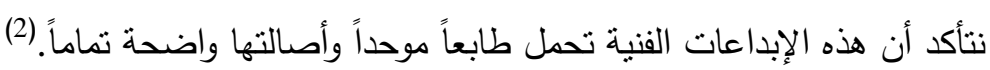

\section{Contemporary Design Thought الفكر التصميمي المعاصر مرحس}

(1) - (1) سورة الحديد، آية 3 .

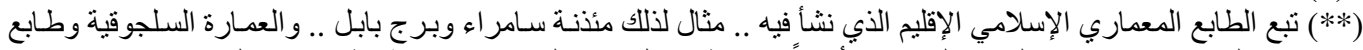

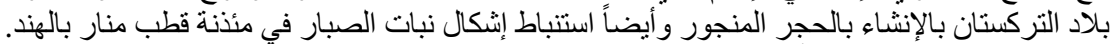

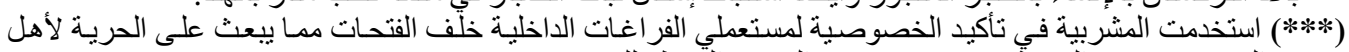

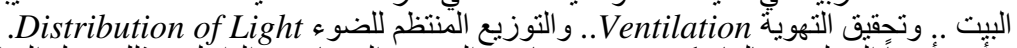

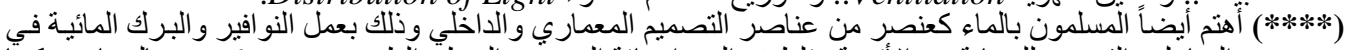

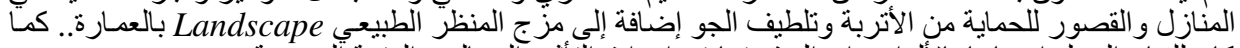

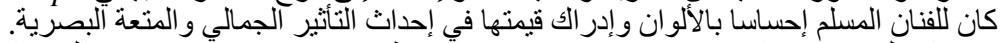

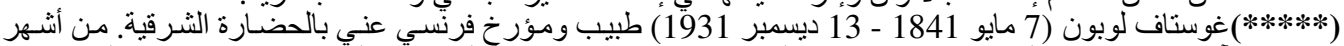

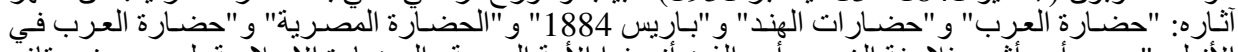

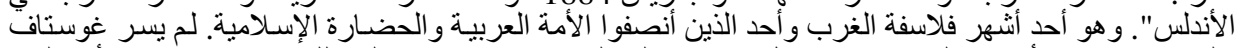

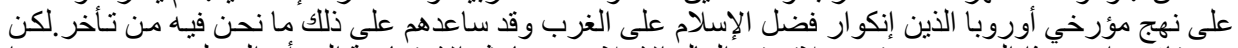

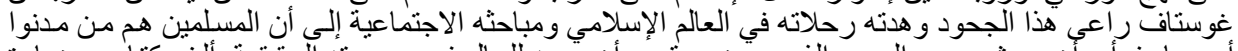

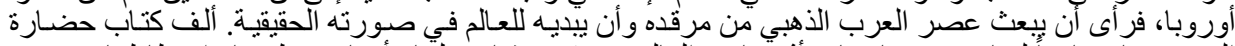

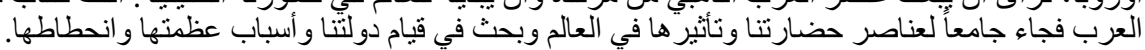

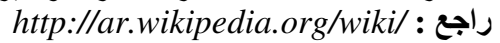

(2) غوستاف لوبون " حضارة العرب " ترجمة : عادل زعيتر ، دار إحياء الكتب العربية، القاهرة ، 1976م ، ص. 482 
كان الدصم في العصور القديمة يجمع بين أكثر من تخصص وموهبة في آن واحد، فنرى أن المفكر والمثاّل والمصور والمعماري ممكن أن تتمثل في شخصية واحدة وإنسان واحد، وبنطور الحياة وظهور

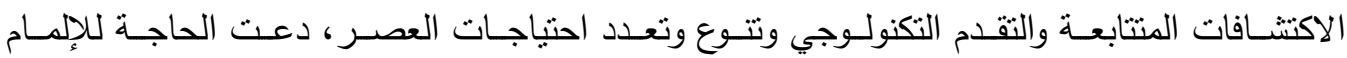

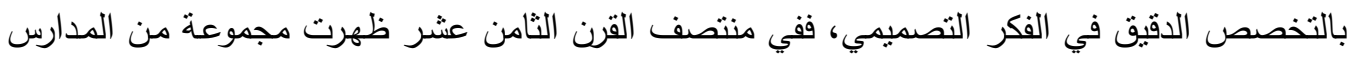

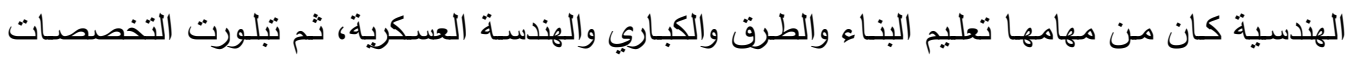

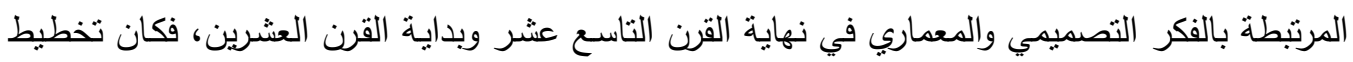

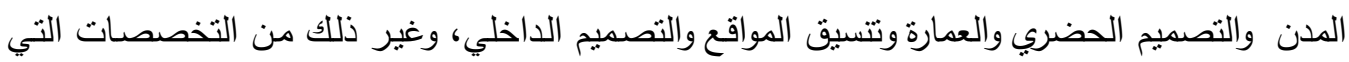

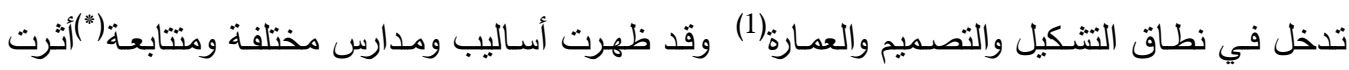

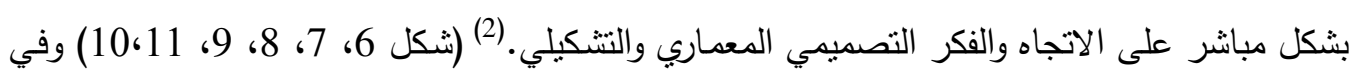

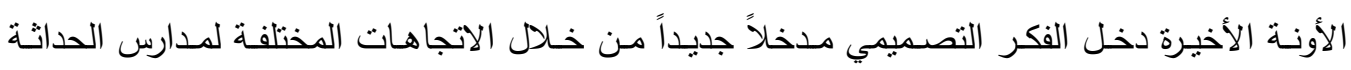
Post Migh technology. Modernism Modernism (الذي نراه سائدا في العالم الآن.(" Sculpture Form

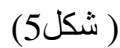

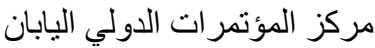

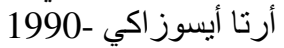

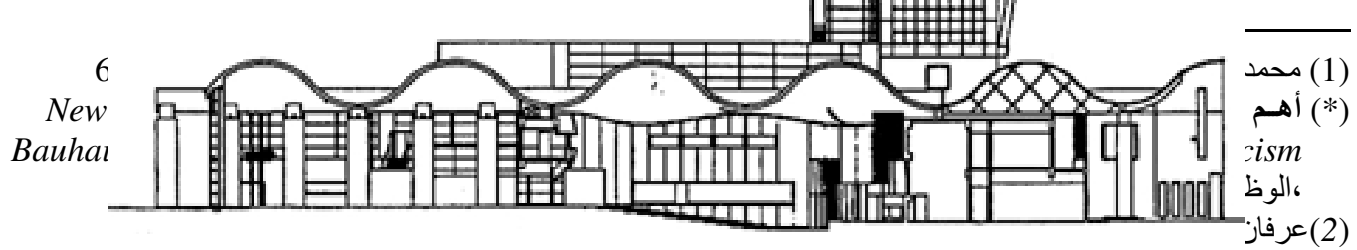

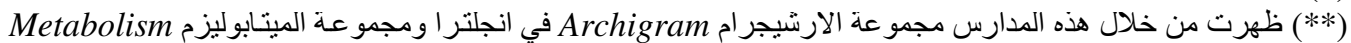

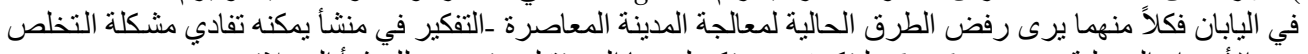

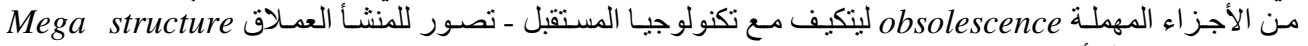
يحتوي مدينة كاملة أو جز الأه منها.

(3) Moffett, Marian\&Others, A World History of Architecture, Laurence King Publishing,

London,2003, p. 560 .

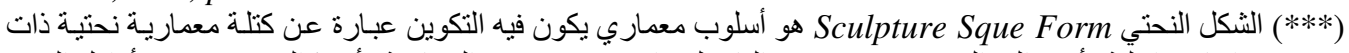

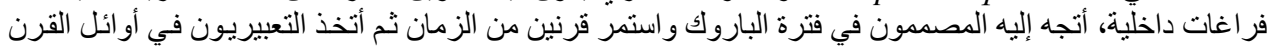

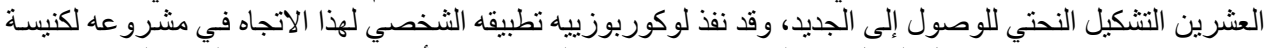

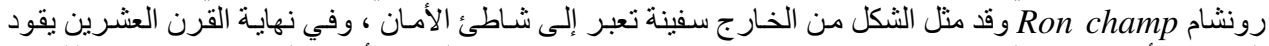

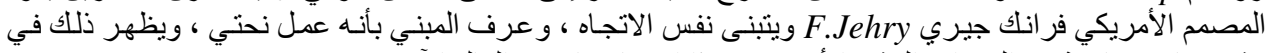
مشرو عاته وخاصئة في السنوات العشر الأخيرة ، وهذا الاتجاه سائد في العالم الآن. 
ترك نصف الأرض كفر اغ أمام المبنى

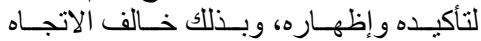
الأمريكي المعروف باستغلانلال الأرض ولو الاتو

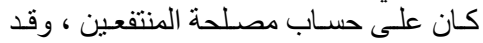

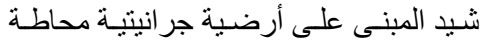

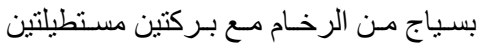
على جـانبي الميدان الذي تركي تركه أمسام البنـاء.

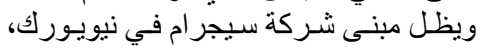

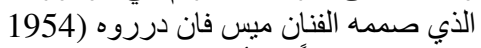

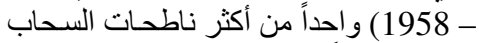

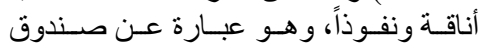

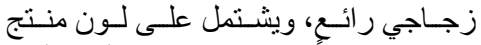

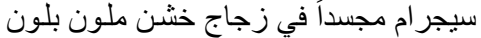
بني خفي.
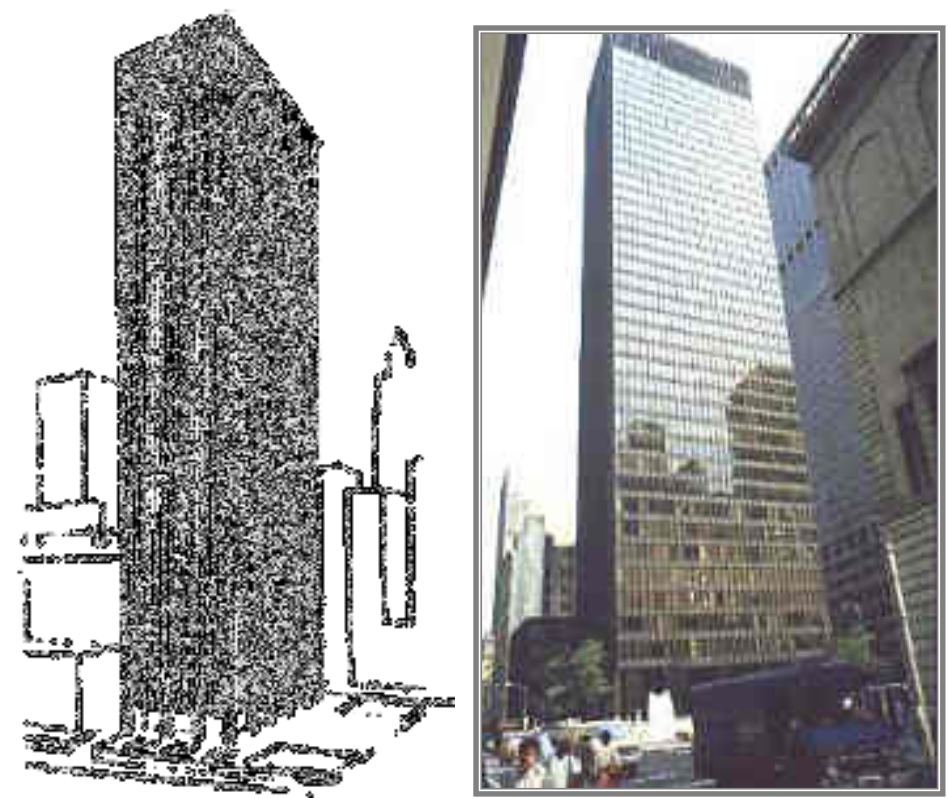

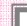

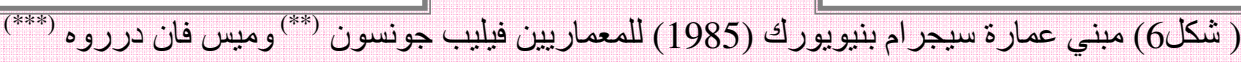
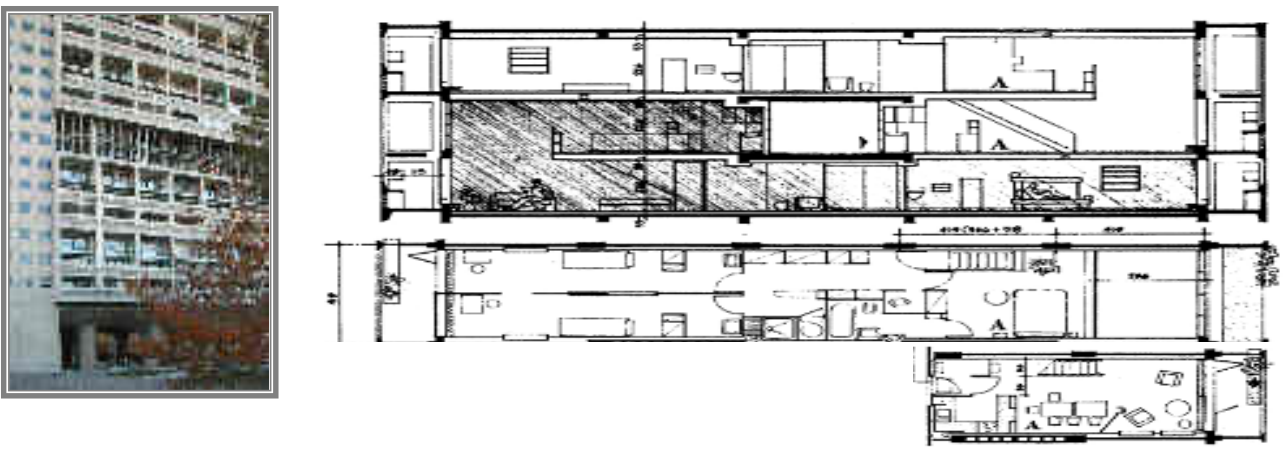
( شكل) عمارة مرسيليا

للمعماري لوكوربوزييه (")
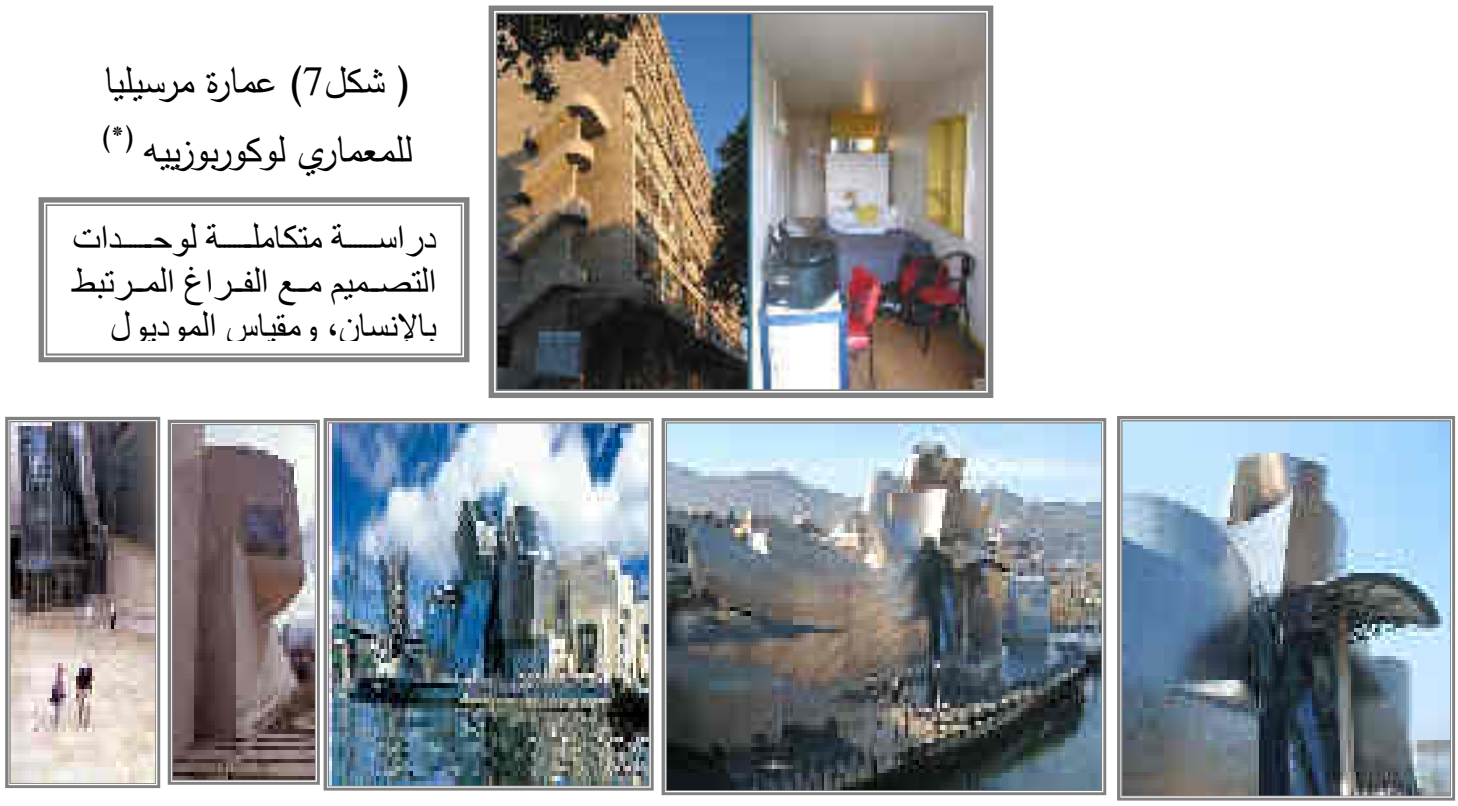

( شكل8 ) الاتجاه النحتي في التصميم - متحف جوجنهايم("**71997، للمعماري فرانك لويد رايت ("*")،

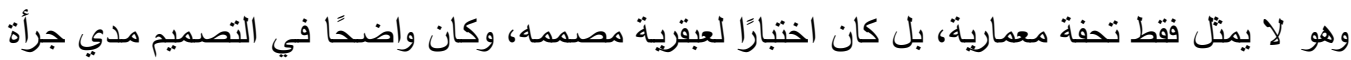

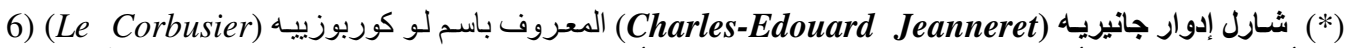

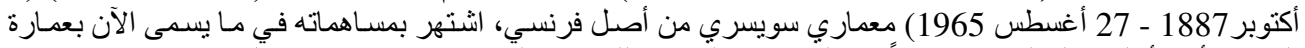

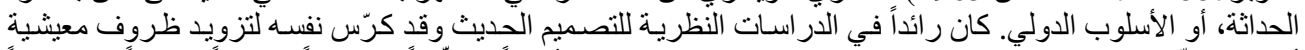

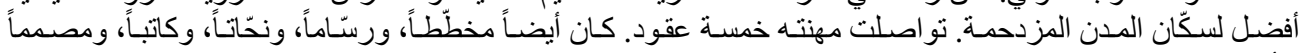
لـأثاث.

http://ar.wikipedia.org/wiki/ : راجد

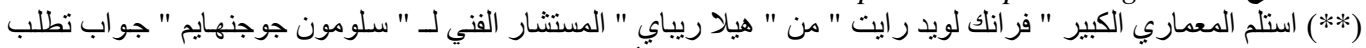

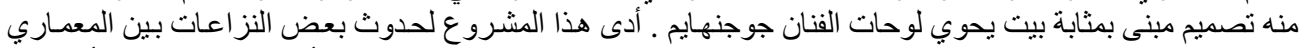

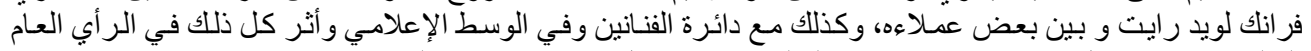

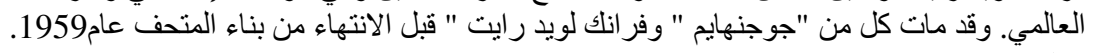
http://www.arabbeat.com/i/6th/museum.htm : راجن

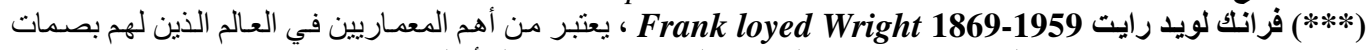

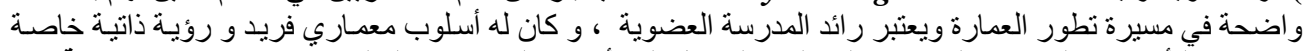

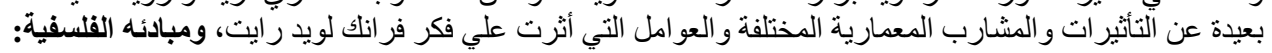

1- المبنى من الطبيعة واليها: يتفق ومظهره الخارجي وتكوينه الداخلي مع صفته و الغرض الذي أنشئ من أجله في زمان معين ومكان بالذات.

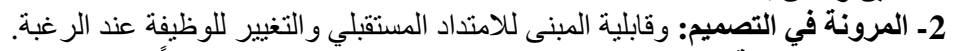

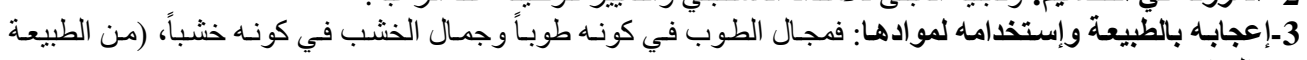
و إليها). 4- تثكيله أبنية تناسب عصره: وتأكيده على أن الثكل يتبع الوظيفة. 
المغامرة والتي نظهر بشدة كلما حاولت اكتثاف المبنى أكثر وأكثر • ومتحف جوجنهايم ("**") يقابله حديقة كبيرة مركزيـة تبعث الراحة النفسية للزائرين وتبعد نسبيا عن زحام نيويورك وضوضـاء المرور .

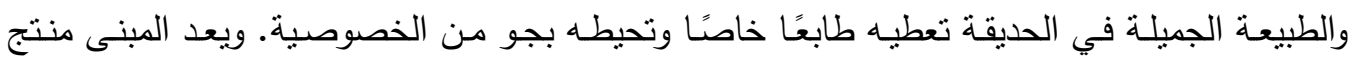

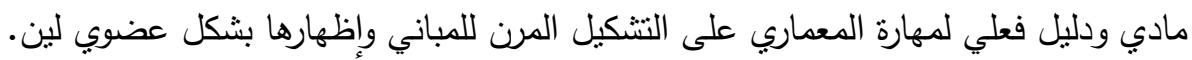
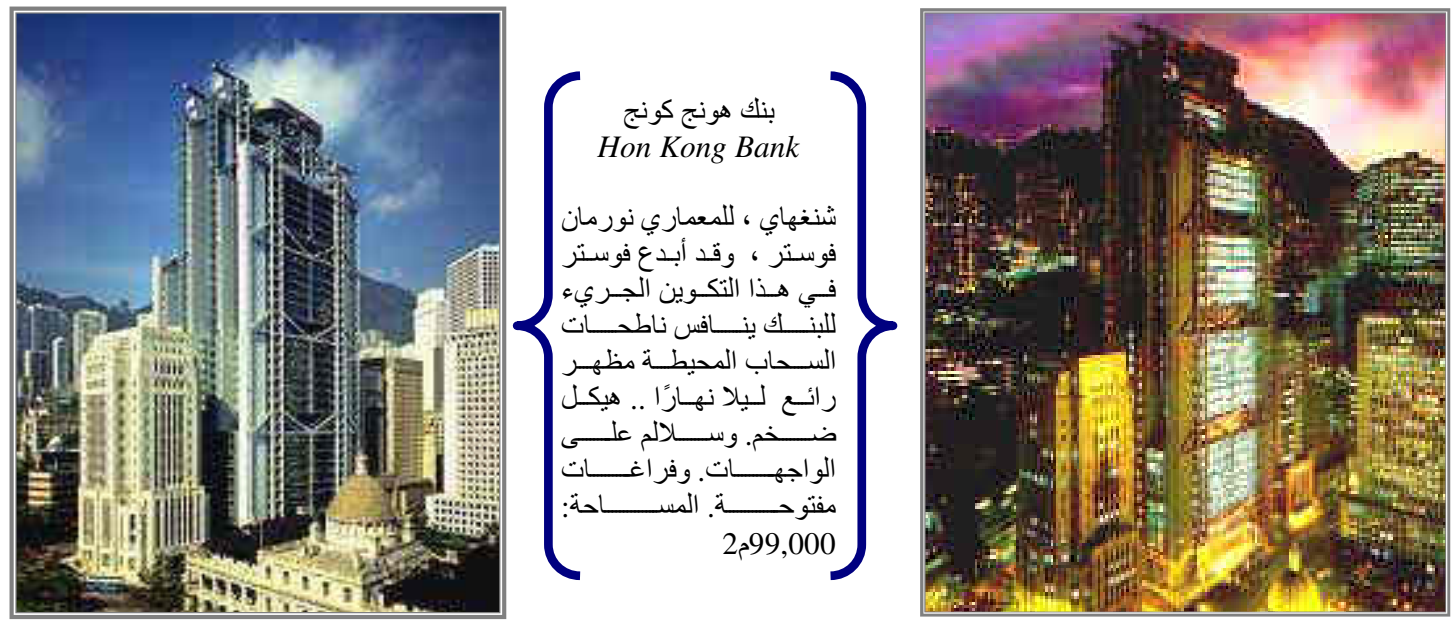

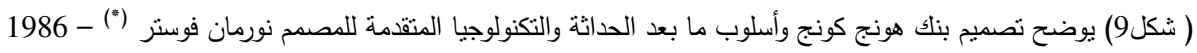
تميز البنك بهيكله الإنشائي المعدني والتعبير الصريح في الواجهات وفي استخدام السلالم المتحركة للربط بين الأدوار المختلفة ويعكس هذا المبنى ذروة تطبيقات جمالية التقنية العالية في عمارة الحداثة المتأخرة ، فهيكله الإنثائي

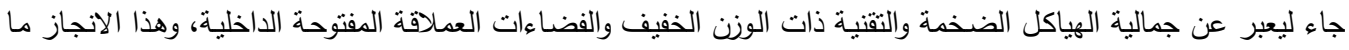

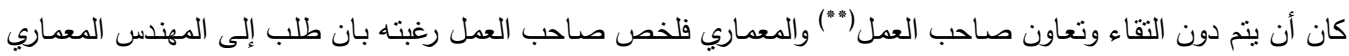
بناء أجمل بنك في العالم، وبالقيام بذلك أعيد اختراع أبراج أو عمارة المكاتب عملياً.

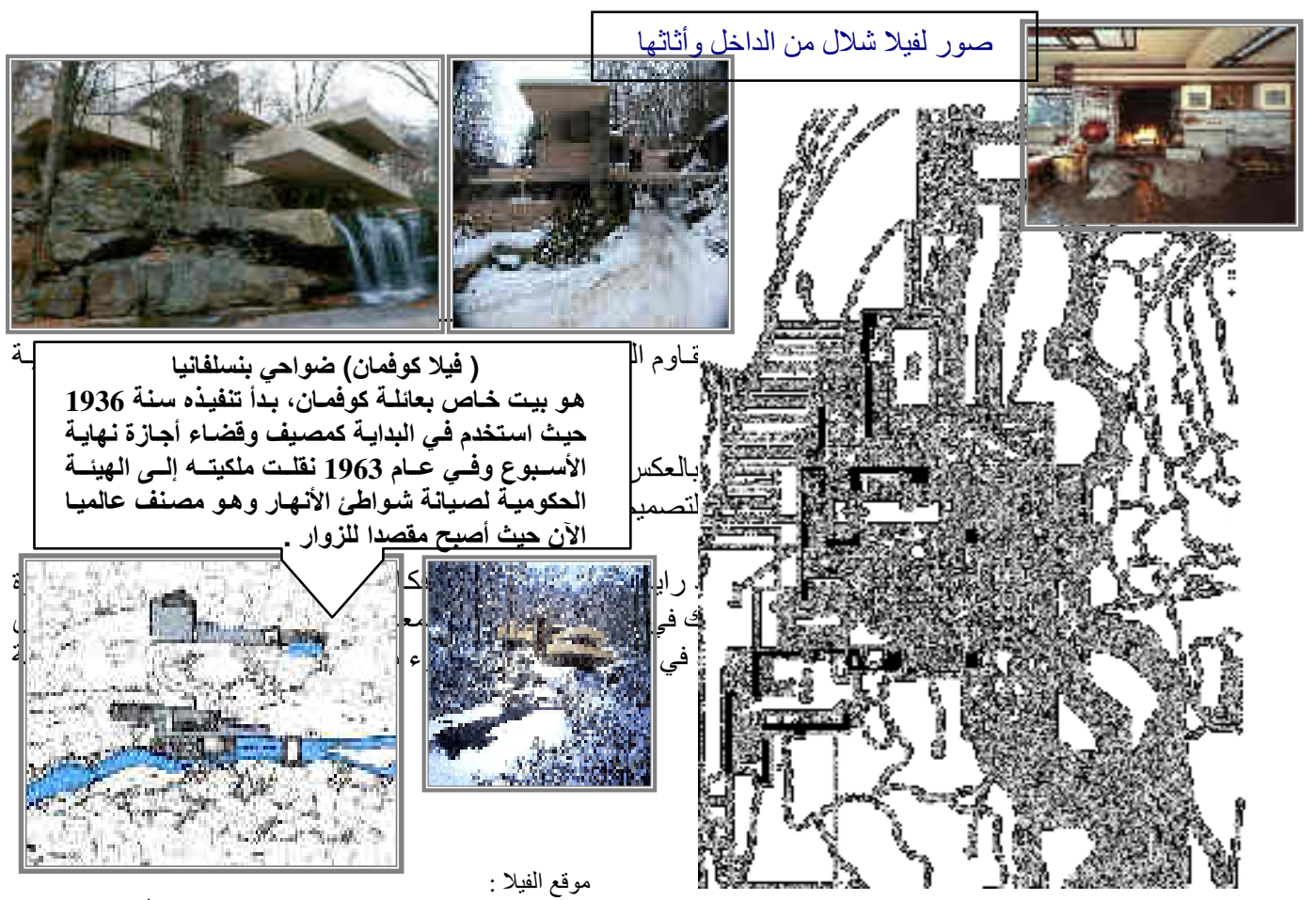


يقول فيليب جونسون Fohnson رائد أسلوب ما بعد الحداثة.Post Modernism . .. أنه لو

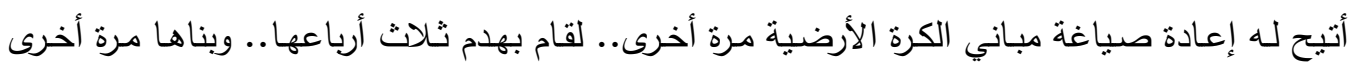

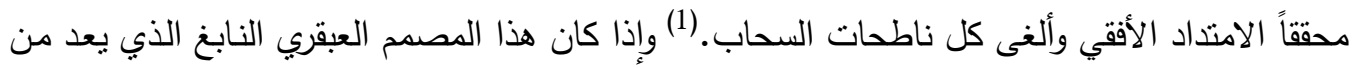

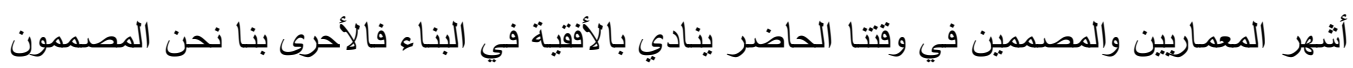

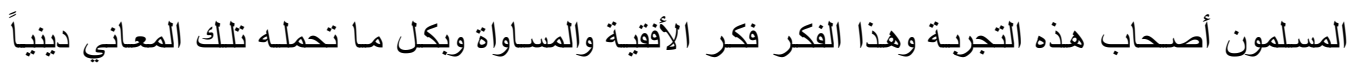

(*) بداء نورمان إعماله في مركز الحداد عام1979ثم هونغ كونج لبناء البنك والذي اعتبر وقتها من أغلى المنشئات في العالم. وعاد إلى وإلى

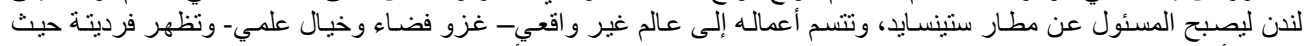

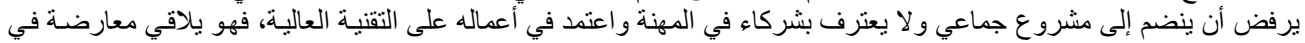

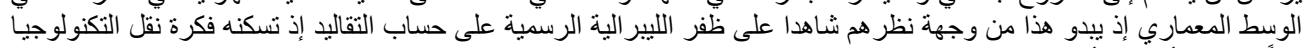

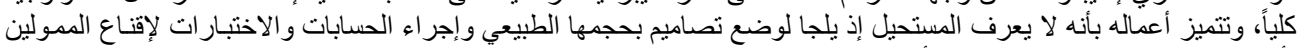

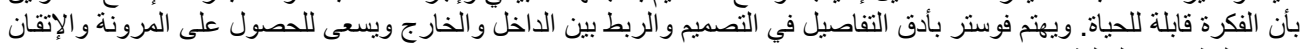
بغض النظر عن التكلفة

(1*) أصحاب المشروع : هونغ كونغ وشنغهاي التعاونية البنكية . الاقتصادي : ليفيث وباليه، نورثكروفت ناييور ونيكولسون .

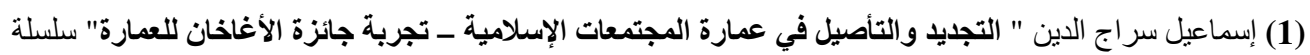

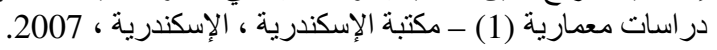


وروحياً وفلسفياً وأيضا تصميميا ، أن نتفهم هذه القيم.. ونعيد اهتمامنا بدراسة المفاهيم الأساسية للتصميم

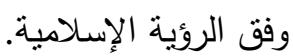

\section{Environmental Pollution\& Inner Space التلوث البيئي والفراغ الداخلي :} البيئة الطبيعية.. بيئة أحكم اله تعالى خلقها.. وأتقن صنعها كماً ونوعاً ووظيفة.. قال تعالى:

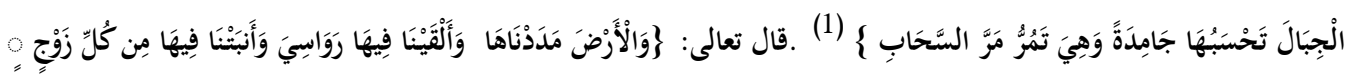

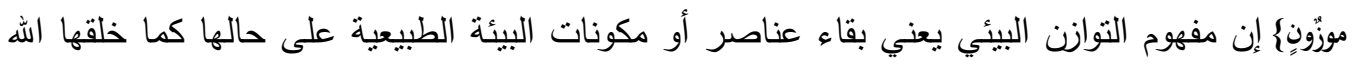

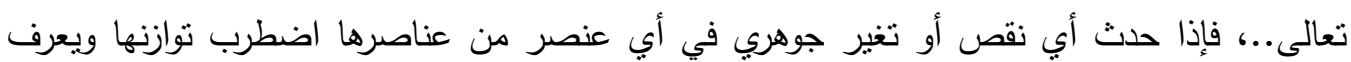

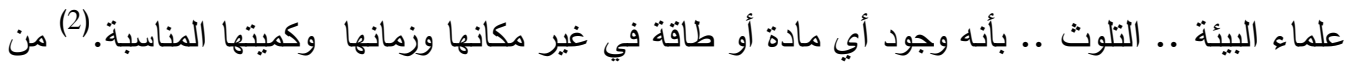

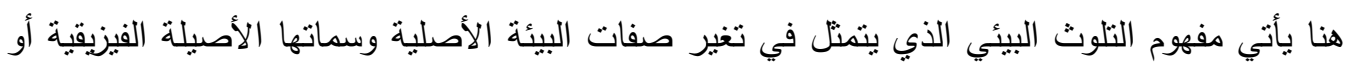
الكيمائية أو البيولوجية وتعرف أيضاً هذه الظاهرة بأنها تغيير الوسط الطبيعي الناشئ بفعل الإنسان.

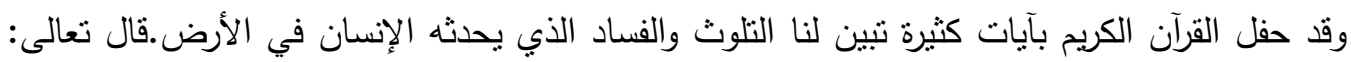

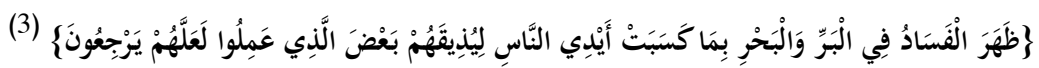

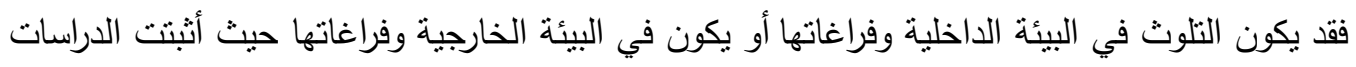

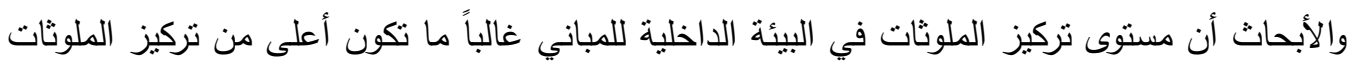

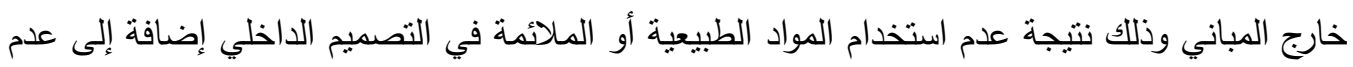

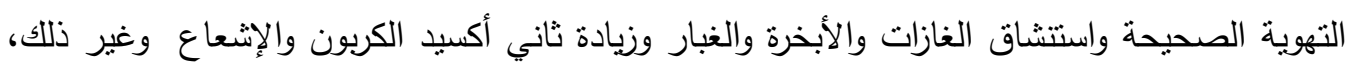

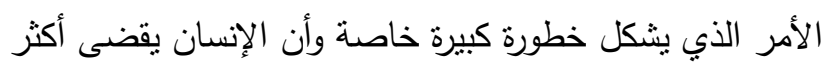

من90\%من وقته ونشاطه في الأماكن الداخلية في الأسواق والمدارس والمطاعم والمكاتب.. الخ ، بل أن الإنسان بقضي65 \% من هذا الوقت داخل مسكنه الخاص.

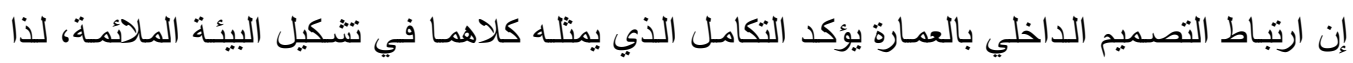
ينبغي علينا أن نعمل على إحداث توازن في ما نقوم بتشييده في الفراغات الداخلية والفراغات الخارجية

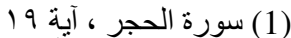

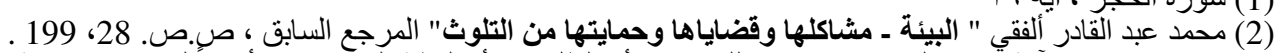

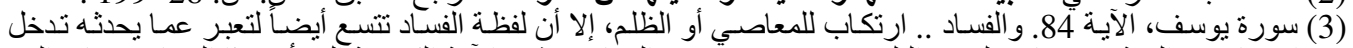

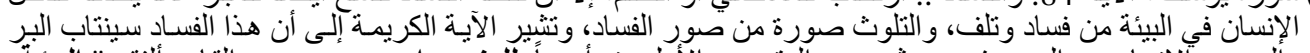

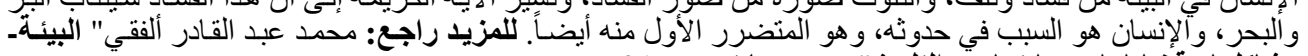

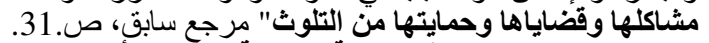

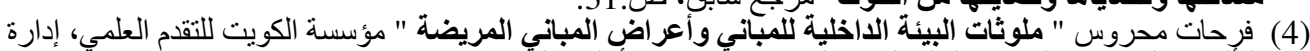

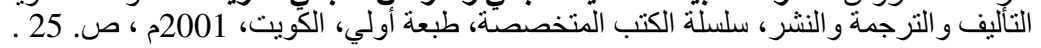


وبين البيئة، حيث أن البيئة المبنية تحل محل جزء من النظام البيئي بتواجدها الحسي الملموس.. وفى

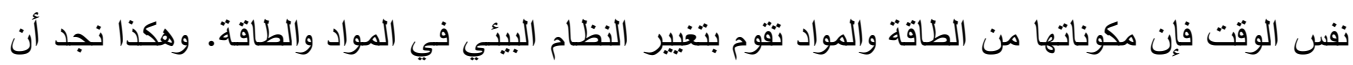
القرآن الكريم قد تحدث عن مشكلة تلوث البيئة قبل وقوعها بنحو أربعة عشر قرناً من الزمان.

\section{Pollution of The Optical Environment 2-2 تلوث البيئة البصرية}

تتوقف درجة التلوث البصري على قدر ما تنتافر فيه البيئة المحيطة من مفردات وعناصر تصميمية.

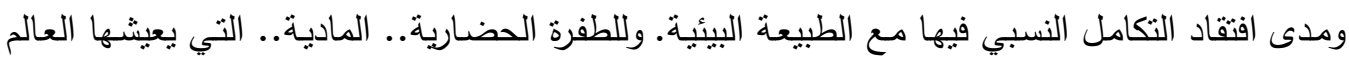

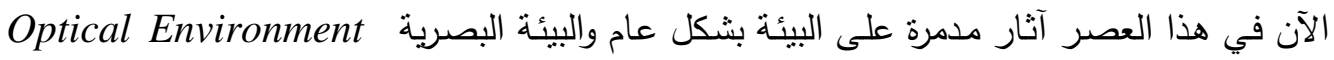

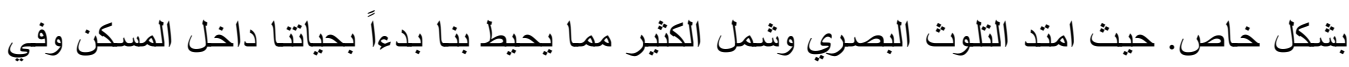

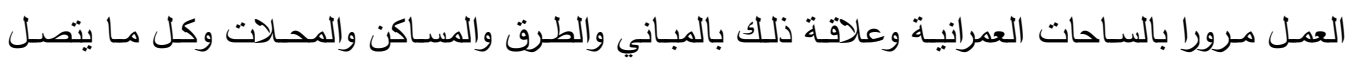

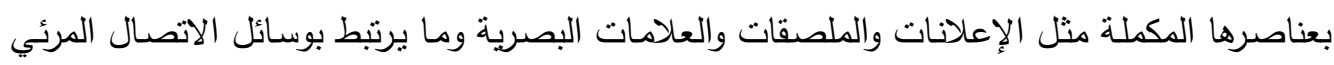

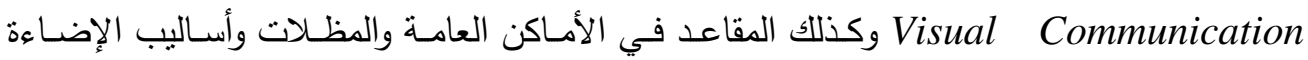

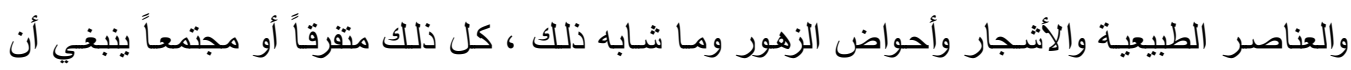
يكون منسقاً ومنسجماً مع التكوين العام.. بحيث تتحقق الملائمة البصرية مع البيئة. إن الأثياء والتكوينات غير المألوفة لنا ثقافيا وبصرياً(1) يمكن أن تقودنا إلى النفور وتبعدنا عن التمييز

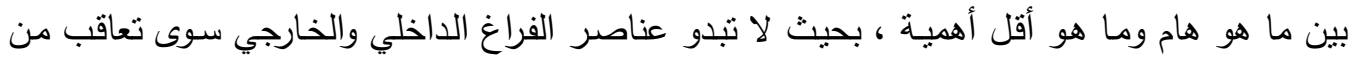

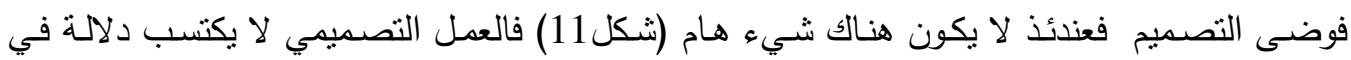
نظرنا إلا عندما نعرف أي أجزائه هي التي ينبغي أن نركز عليها، فئن فالتتظيم التصميمي والتشكيلي أثبه

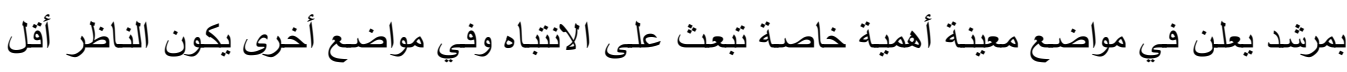
انتباها.
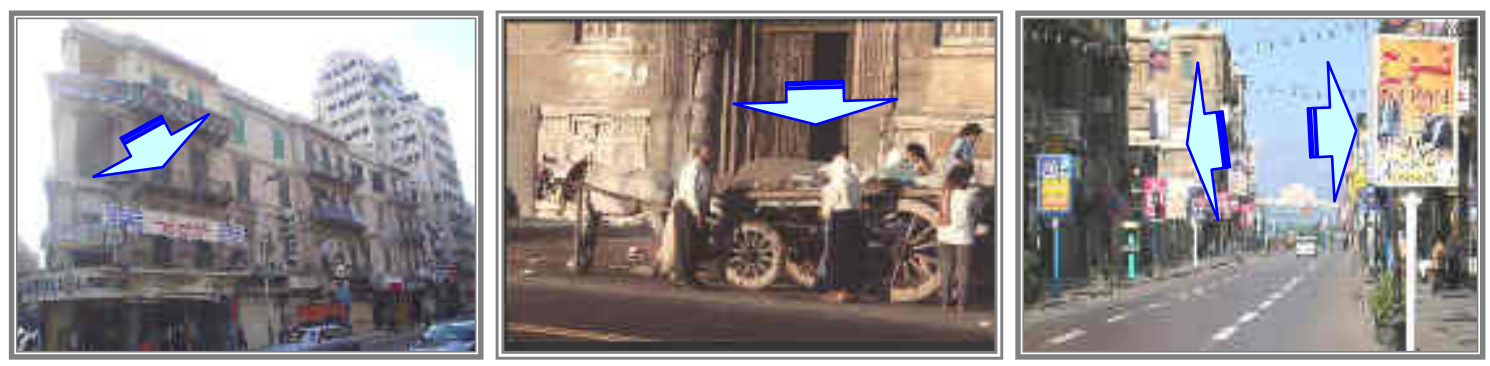

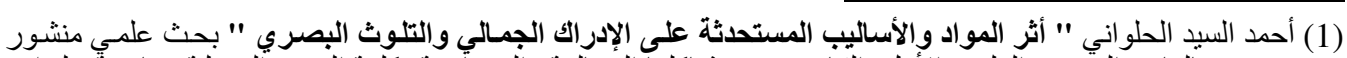

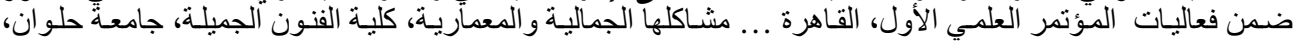


التشوه في المباني بالإعلانات

$$
\begin{aligned}
& \text { تتشوه الأرصفة والفراغات العمرانية إحدى مظاهر التلوث البصري } \\
& \text { بالتوزيع العشوائي للإعلانات } \\
& \text { والملصقات }
\end{aligned}
$$

( شكل 11 ) عشوائية التصميم تقودنا إلي النفور وعدم التمبيز بين العناصر المهمة - مجموعة صور

$$
\text { توضح بعض من مظاهر التلوث البصري }
$$

يرى " برودبنت Broadben " أن موقف وقبول الإنسان العادي وتذوقه وإحساسه تجاه العمل يرجح نجاح أو فثل العمل التصميمي دون موقف المعماري والمصدم نفسه. (1) وإذاذ

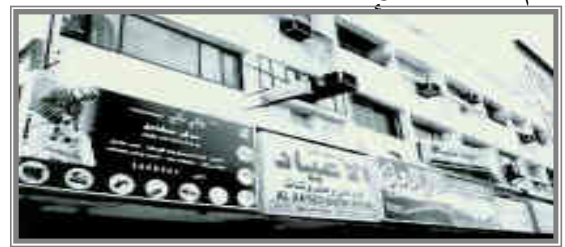

( شكل 12) أحد مظار ع التلوث البصري

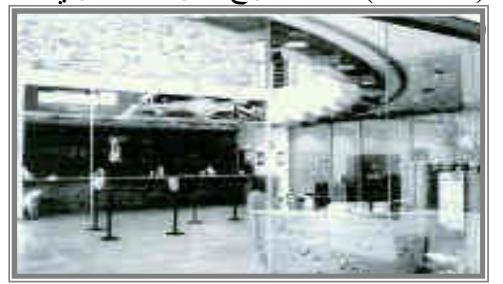

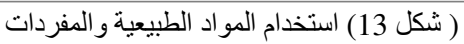

و العناصر التر اثية في التصميم الداخلي التئي

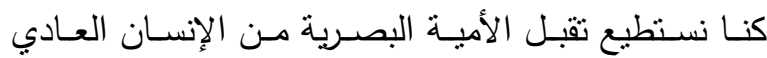

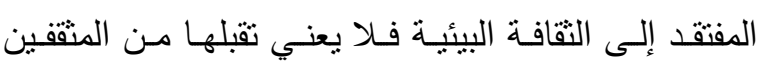

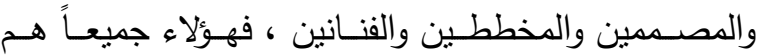

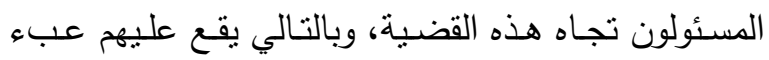
الصمود والمقاومة لكل مـا هو دخيل على بيئتنا وعاداتتا وسلوكيات الحاضر.(2) لذا عليهم الدور في تتمية الوعي لئي

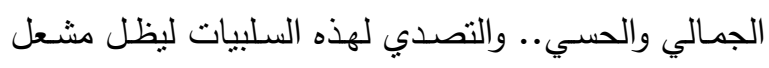

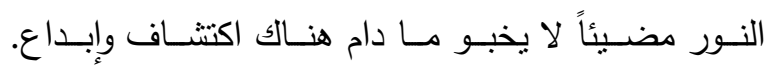

2-2 العناصر المؤثرة في التلوث البصري Effective Elements in Optical Environment: عند تتاول العناصر التتكيلية مثل( المادة - الضوء- اللون) في العمل التصميمي نفسح بالتالي المجال

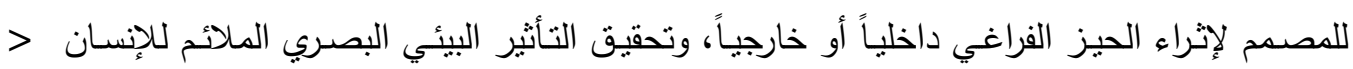

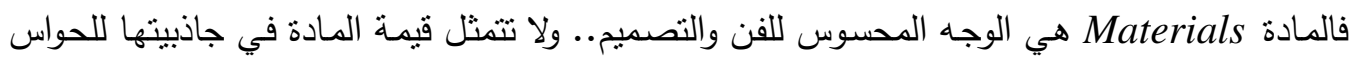

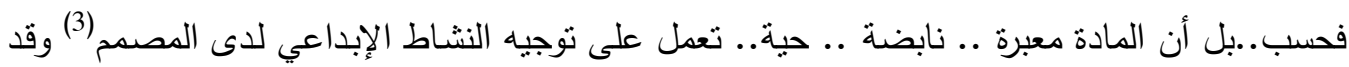

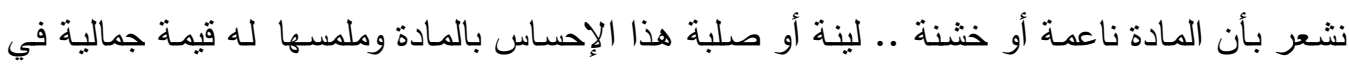

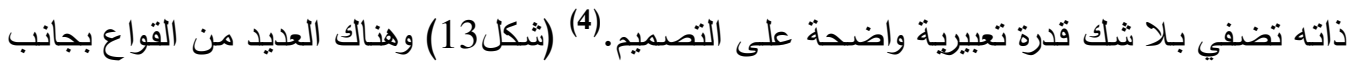

(1)Broadbent. G; Design in Architecture, Architecture \& the Human Sciences' John Willy \& Sons, New York 1968 , p.11.

(2) إسماعيل طه نجم " الفنون التثكيلية وأثرها على الحياة اليومية " المؤتمر العلمي الرابع ، كلية الفنون الجميلة، جامعة

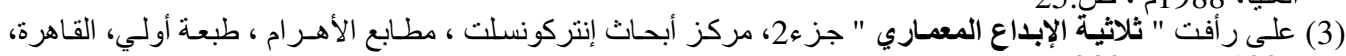

(4) Koji Yoji, A. Japanese Touch for your Home, Japan, 1992, p. p. 71 , 73 
خيال المصمم المبتكر الذي يعيد اكتشاف المادة لإيجاد طرق جديدة لاستخدامها. كما أن الضوء يعتبر

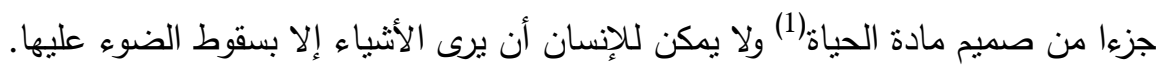

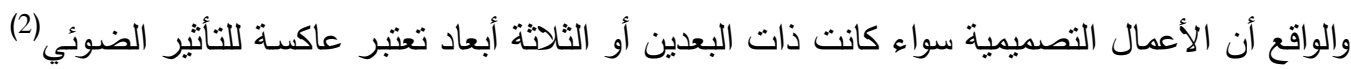

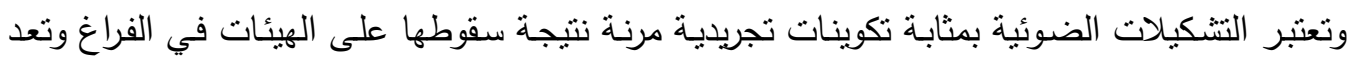

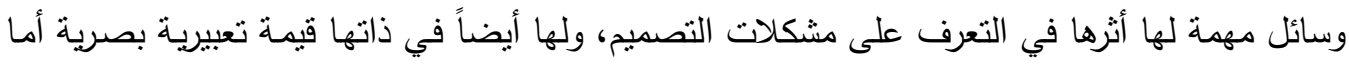

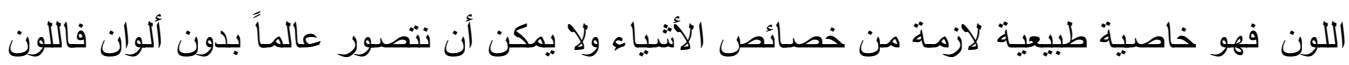

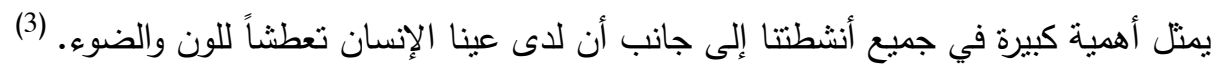

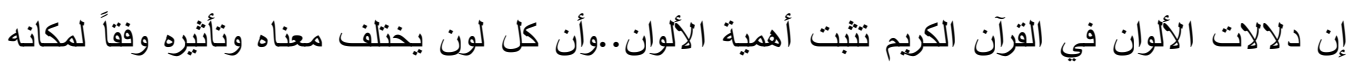

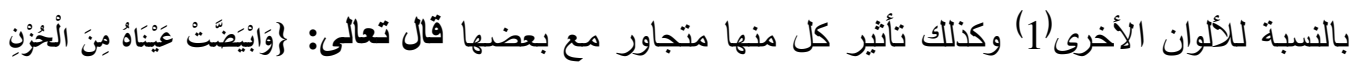

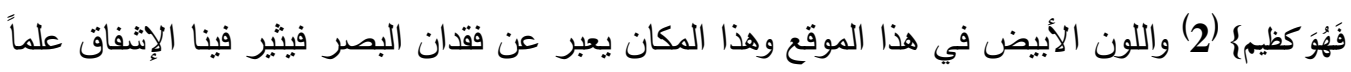
بأن اللون الأبيض يعبر عن معاني الصفاء والنقاء والطهر والثفافية.

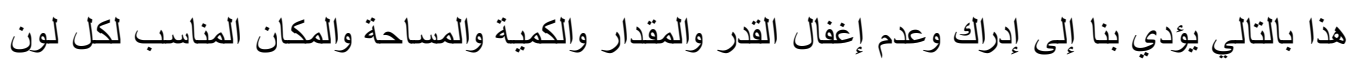

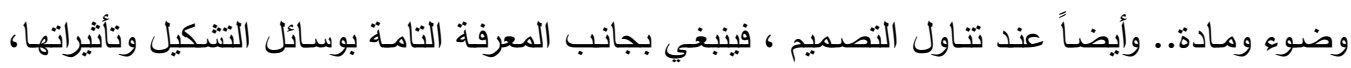

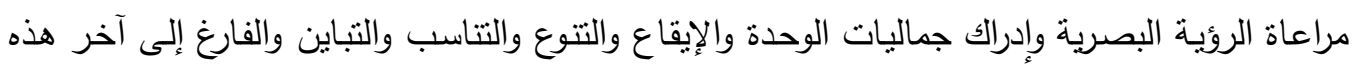

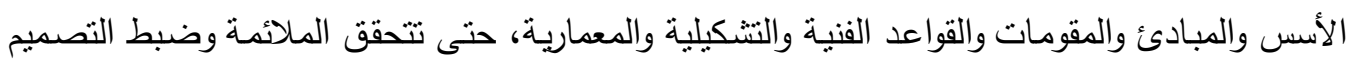

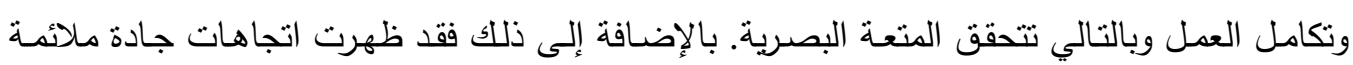

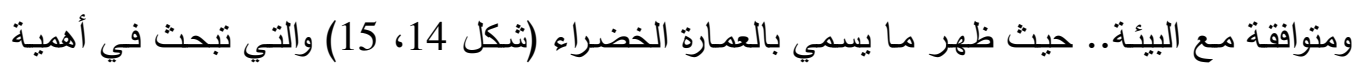
العلاقة بين تصميم الفراغات الداخلية والخارجية وبين الطبيعة والتغيرات البيئية المحيطة. (شكل16، 17) وقد ظهر هذا الاتجاه من أجل مواجهة المخاطر والمشكلات البيئة

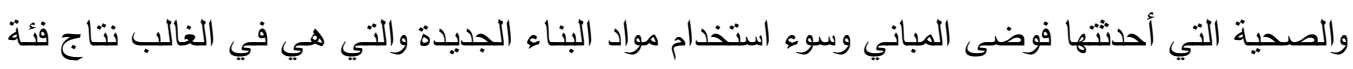
دخيلة من غير المتخصصين والتي لا تأخذ في اعتباراتها التصميمية بالبعد البيئي.

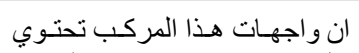
على مجمو عـة كبيرة مـن الخلايـا الثمسية من اجل امتصاص الطاقة

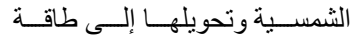
كهربائية كما اعتمد إنشاء واجهات

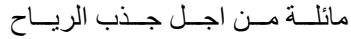
وتوجيهـا نحو الفراغـات الداخلية الرية

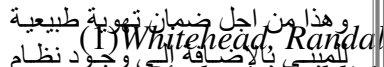

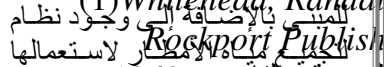

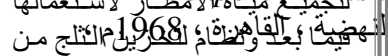

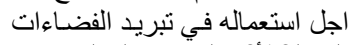

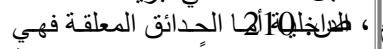
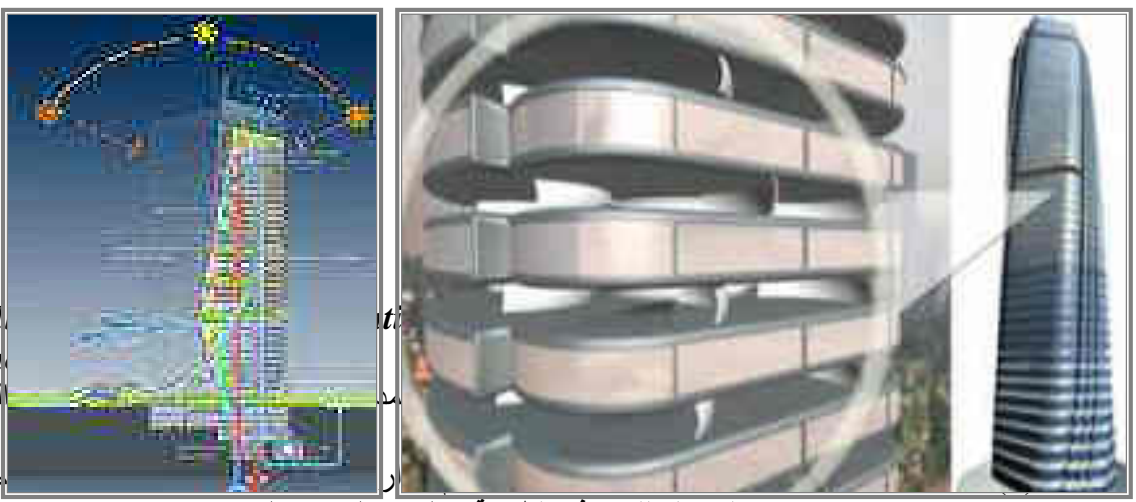

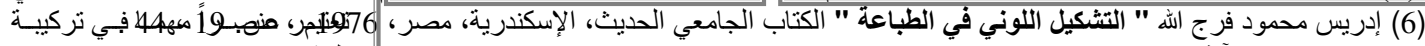

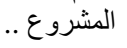


(2) (شكل 15)

مشروع في سنغافورة للمعماري نورمان

فورستر ("*)
(شكل 14) (1) العمارة الخضراء والعمارة المستدامة

ناطحة سحاب متحركة في دبي (")

والعمـارة الخضـراء(****) تلبـي احتياجـات النـاس ومنطلباتهم من الراحـة والصـحة العامـة وتزيد من القدرة الإنتاجية للإنسان وتزيد من الاعتماد على الطاقة النظيفة مثل الثمس والرياح وغيرهما وتسمح باستعمال

(1)http://www.archnewsnow.com/features/images/Feature0161_04x.jpg

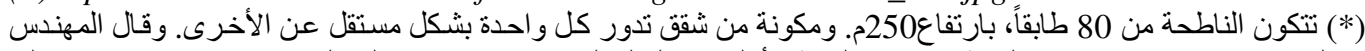

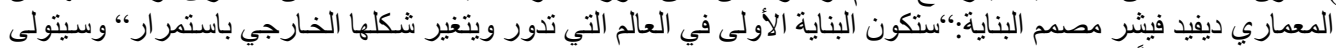

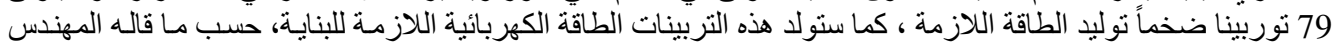

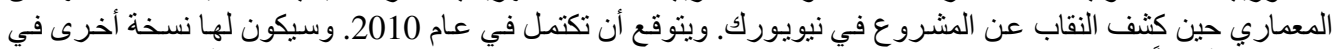

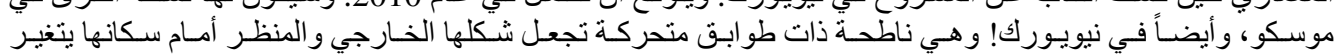

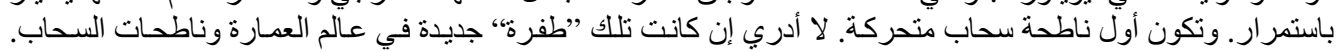

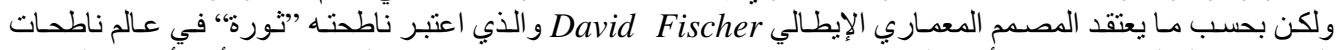

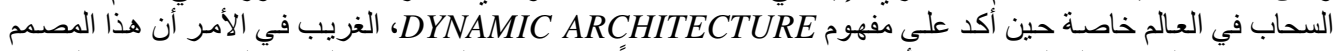

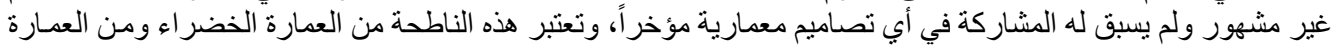

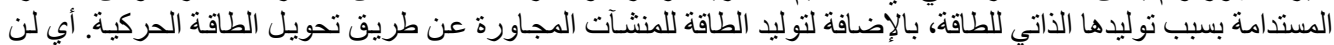

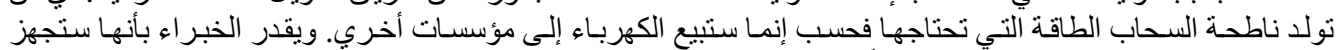

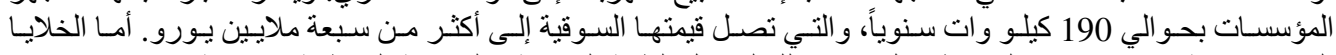

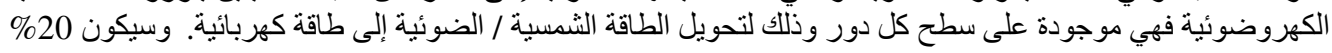

من السطح مكثوف بشكل دائم للشمس. أما بالنسبة للمو اد المستخدمة في البناء أو التشطيب فهي مواد صديقة للبيئة ويمكن إعادة تدوير ها كالحجر و الخشب و والزجاج.

(2)www.a7bk-a-up.com/pic/ufk33417.jpg

(**) يعتبر المهندس المعماري Norman Foster من رواد العمارة الخضر اء في العالم و هو يستعمل أخر مـاوصلت إليه

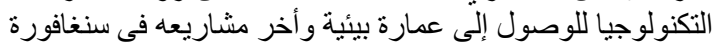

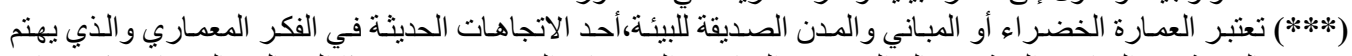

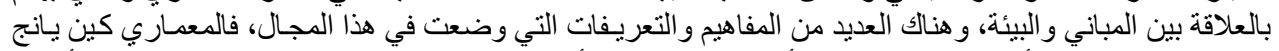

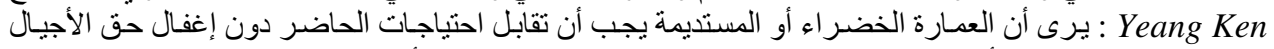

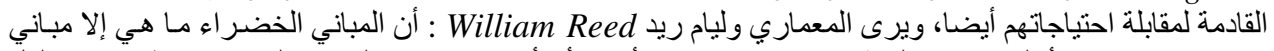

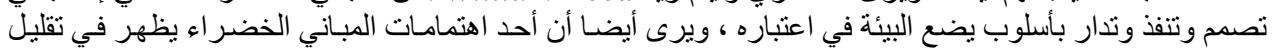


الطبيعية للبناء(1) وتعد تجربة المعماري الفنان حسن فتحي (شكل 18) مرحلة مهمة ومدرسة فنبة أضافت كثيرا للتصميم المتوافق مع البيئة خاصة وأن حسن فتحي كان يبدأ التصميم من الداخل.

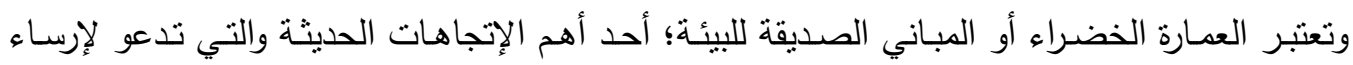
دعائم فكر معماري وبيئي جديد بصورة أكثر عمقا وفهما وارتباطا بالطبيعة وبالأنظمة البيئية ككل. (2)

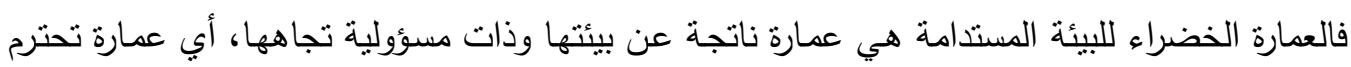

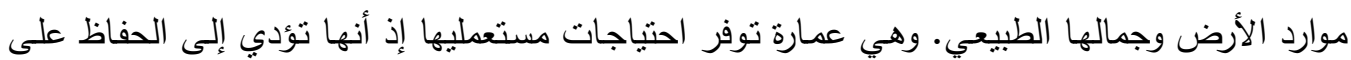

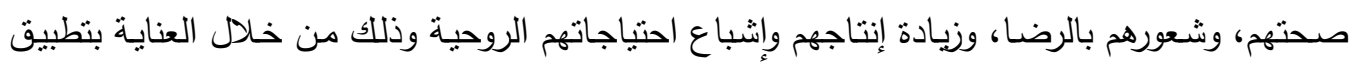
الاستراتيجيات المؤكدة لاستدامة البيئة.

ويمكننا النظر والحكم على العمل التصميمي والمعماري بمحتوى النقاط الآتية(4) :

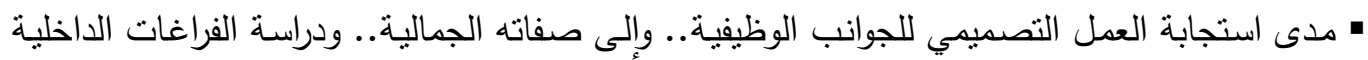
وتأثيثها وكذلك الفراغات الخارجيـة وعلاقة ذلك بالمـادة والضوء واللون ومختلف مجموعة المفردات التصميمية وتقييم تأثنراتها المادية والحسية. • مكانـة العمل التصميمي باعتباره جزءاً من الثيارات والأسـاليب والمدارس الفكرية ومدى مساهمته في وني تطويرها وبلورتها.

• العمل التصميمي في سياقه الحضاري.. يعبر عن مدى الملائمة والتوافق مع التراث الحضاري. • العمل التصميمي في سياقه المادي.. ويشمل دراسـة إيجابيات وسلبيات العلاقة بين التصميم والبيئة التئة

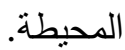
• تأثثر العمل المعماري في الاتجاهات المحلية ومدى الإضافة إلى المستوى الفكري للمنطقة.. والاهنمام

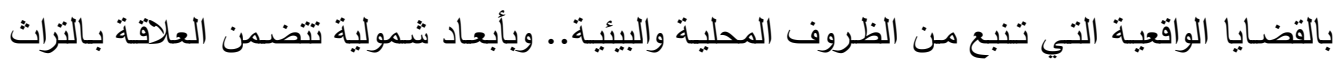
والهوية.

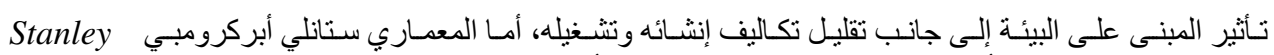

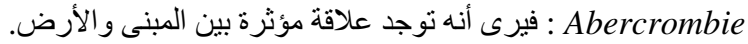

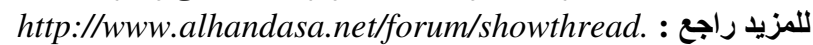
(1) على رأفت " العمارة البيئية الخضراء والتنمية العمر انية " مجلة عالم الفكر، ، عدد خاص عن العمارة، المجلس الوطني

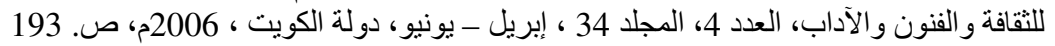

(2)www.sabraeng.com/vb/showthread.php?t=1217 - 127k

(3)http://www.omranet.com/vb/showthread.php?t=27

(4) إسماعيل سراج الدين " التجديد والتأصيل في عمارة المجتمعات الإسلامية " ، تجربة جائزة الأغاخان للعمارة ، سلسلة دراسات معمارية 1، الإسكندرية ، مكثبة الإسكندرية ، جمهورية مصر العربية ، 2007م ، ص. ص. 567. 


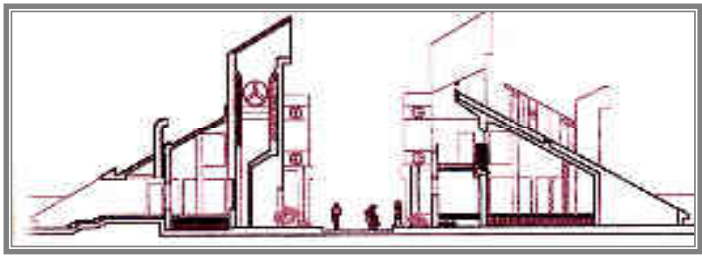

- يعتبر البعد البيئي هامـا جدا يجب مراعـاة

تحقيقــة فـي الوحـدات الســكنية لأن البيئــة

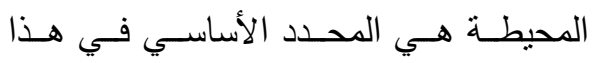

المشروع والتغلب على صسابها هو التحدي

الحقيقي.

- البعد البيئي للمشروع يحقق كفاءة العزل التام

$$
\text { للهواء داخل الوحدة. }
$$

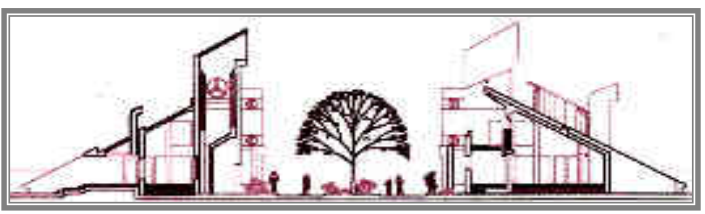

- إمكانيـة التحكم في الحرارة المرغوبـة داخل

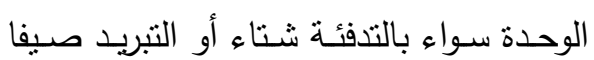

$$
\text { بوسائل طبيعية. }
$$

- تصميم الثكل الخارجي متفاعلا مـع البيئة

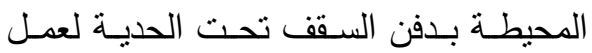

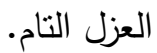

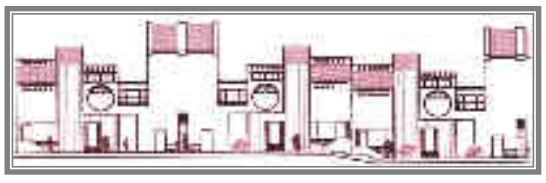

( شكل 16) قطاعات مارة بالوحدات لإحدي التصميمات الفائزة في مسابقة العمارة الخضراء بمنطقة

$$
\text { نوشكي - مصر }
$$

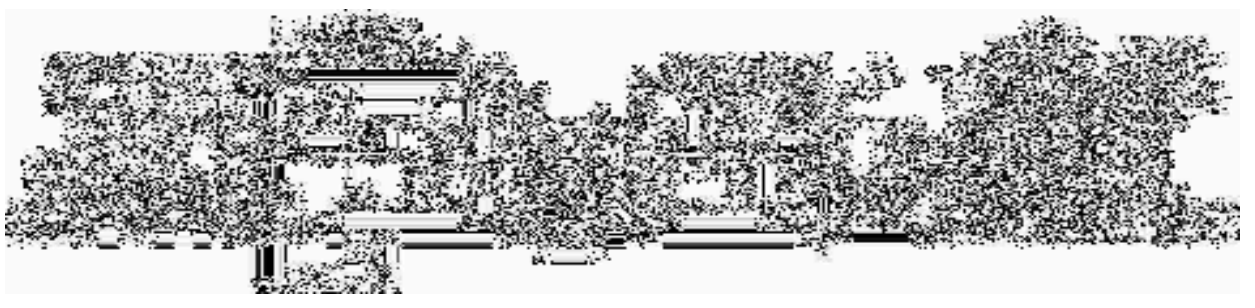

$$
\text { ( شكل } 17 \text { ) فطاع منظوري يوضح العناصر المتو افقة مع البيئة }
$$

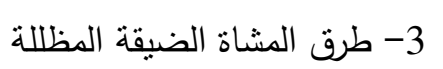

6- في في المنـاطق الرطبـة يمكن

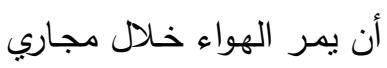

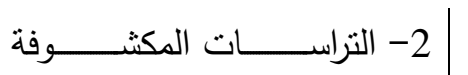

للاستخدام في الليالي الحارة

| 5- وضع نوافذ مطلة على أفنية
1- مجمعـات شمسـية لتـوفير

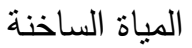

4- الفتحــات العلويــة ( أســفل

الأسقف) والبلاطات السميكة 


$$
\begin{aligned}
& \text { فـي الحـوائط مـزودة بـالمواد } \\
& \text { ماصة للرطوبة. }
\end{aligned}
$$

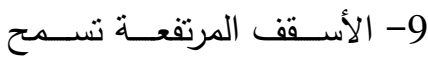
بحركة الهواء البارد.

12- حركة السبارات تم حظرها

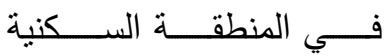
لتعارضـها مـع حركـة المشـاة

$$
\text { وتخفيض الضوضاء. }
$$

15- الحـوائط الخارجيـة سـميكة

وذات فتحات محدودة لنقليل

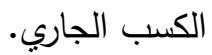

مظلالــة يقلـل مـن اكتسـاب الحرارة وشدة الاستضاءة

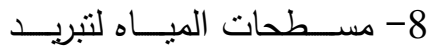
الهواء الداخل إلي الملاقف .

11- المياه والخضرة في الأفنية الخاصــة والحـــائق العامــة تســاعد علـى تبريــــ الهـواء وترشيحه هن الأتربة

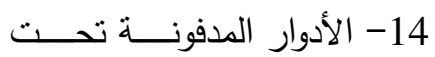

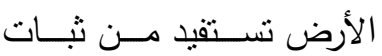

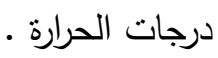

تحافظ على بردة الأسقق

7- ملاقف الهواء تلتقط نيارات الهواء

10- المشــربيات والمخرمـــات

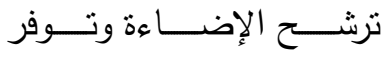
الخصوصية

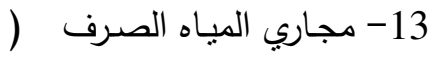
من المطابخ والحمامات ومياه الأمطار) توجها إلي أحواض تجميع تستخدم في الحدائق العامة
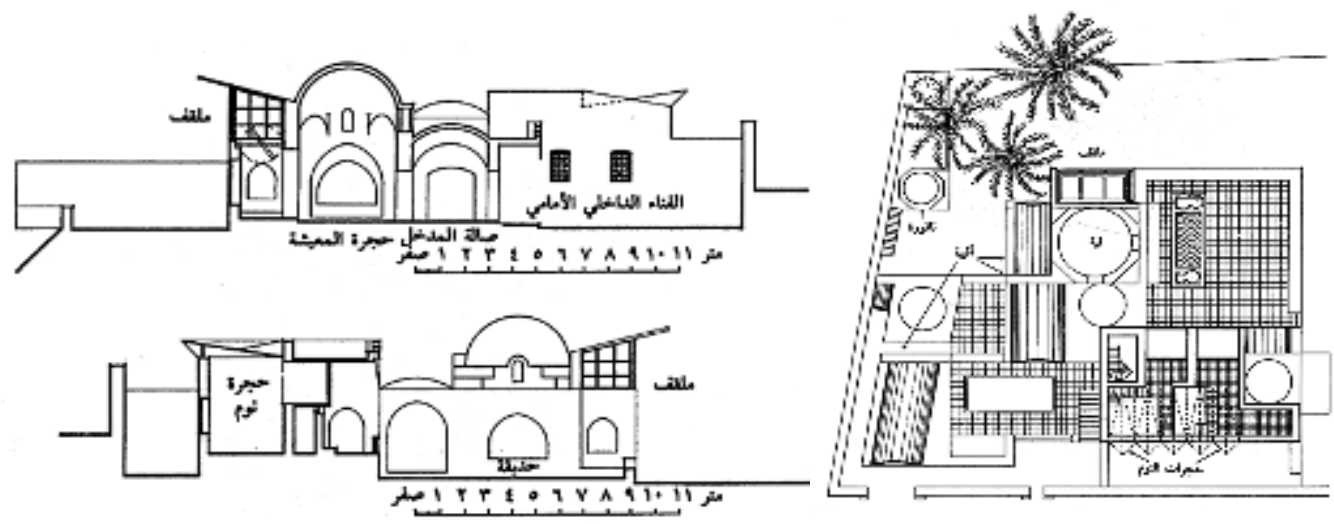

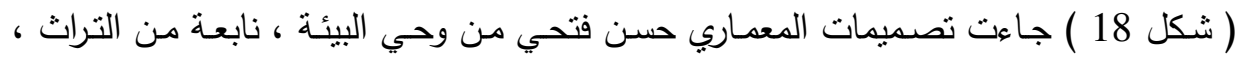

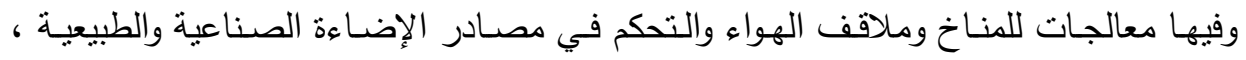
واختيار مواد البنـاء المناسبة لطبيعـة البيئة والمنـاخ ، إلي جانب معالجته لعناصـر التصميم الداخلي ، وكأنه يبدأ عملية التصميم من الداخل إلي الخارج ( منزل فؤاد رياض - القاهرة )

\section{3- مفاهيم الاستدامة والعمارة الخضراء:}

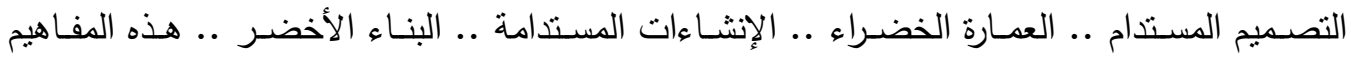

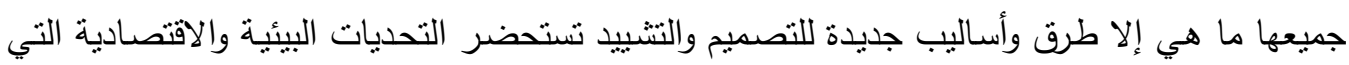
ألقت بظلالها على مختلف القطاعات في هذا العصر ، فالمباني الجديدة يتم تصميمها وتتفيذها وتتشغيلها 
بأساليب وتقتيات متطورة تسهم في تقليل الأثر البيئي، وفي نفس الوقت خفض التكاليف وعلى وجـه

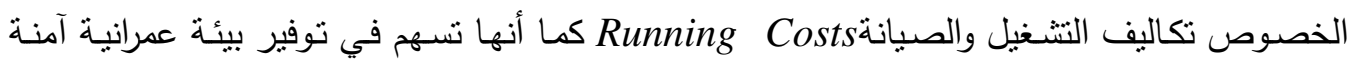

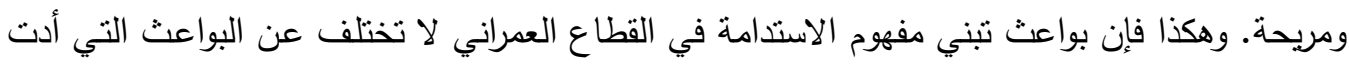

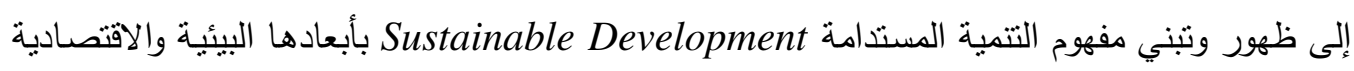

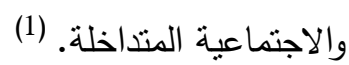

\section{Design \& Islamic Environment التصميم والبيئة الإسلامية.}

التراث الإسلامي بصفة عامة، والفني والمعماري بخاصة نراث إنساني ديني وحضاري ديني ودنيوي، أي الإسيه هو متكامل يجمع بين أحكام الوحي الإلهي ونتاج العقل البشري وفي ظله التقى العلم والإيمان وعمارة

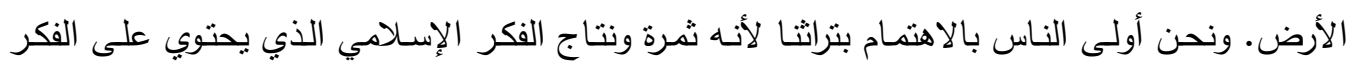

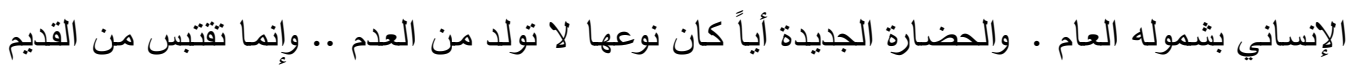
وتسهم فيه بالإضافة والتعديل، ثم تقدم حلقة جديدة من السلسلة الحضارية والفكرية. فحضارة الإغريق

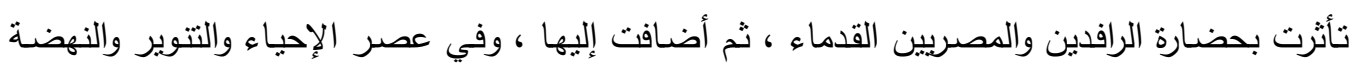

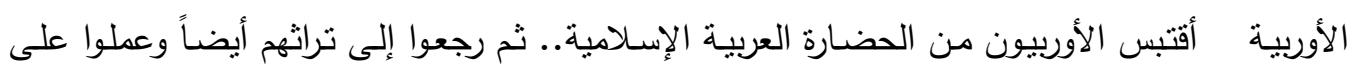

إحيائه.. بل وبنوا على هذا وذاك أسس انطلاقهم إلى الحضارة الحديثة التي يعايشها العالم الآن. (2)

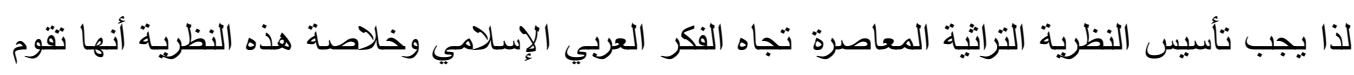

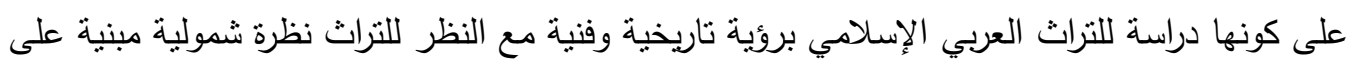

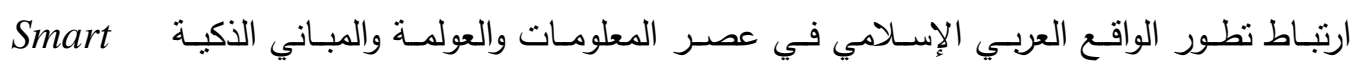

\section{(3) وتكنولوجيا النانو Buildings}

إن مفهوم الحداثة في الفكر والفن والتصميم يقوم على تـلازم بين الحداثة والأحوال التاريخيـة التراثية

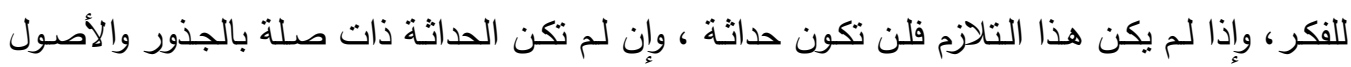

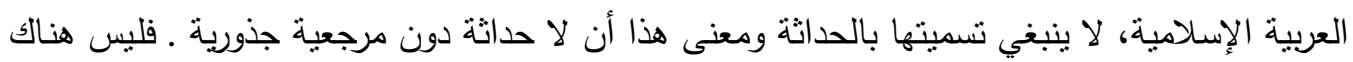

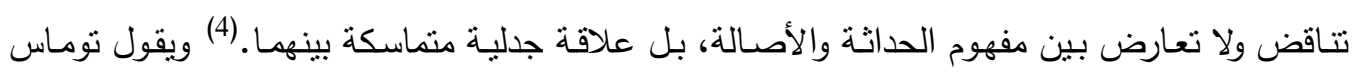

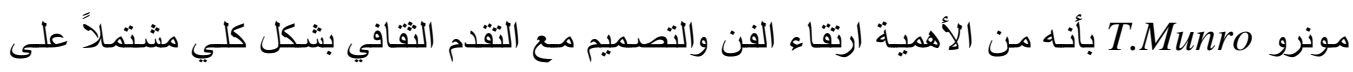

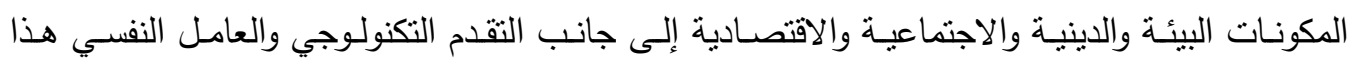

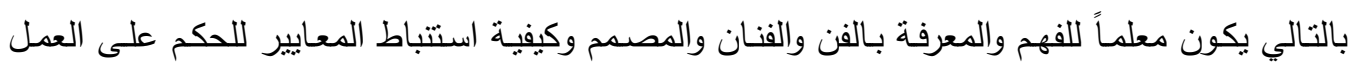

(1)http://www.arab-eng.org/vb/t19561-2.html

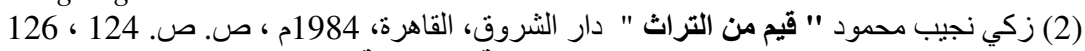

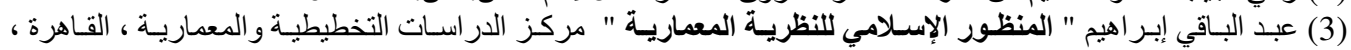

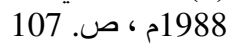
(4) حسين مروة " النزعات المادية في الفلسفة العربية " الدار اللبنانية للطباعة والنشر ، بيروت ، 1982م، ص. 38 . 
التصميمي، لذا فإن الإبداع التصميمي والفني يكون بمثابة وحدة متكاملة ومتلازمة مع الثقافة تتأثز بها

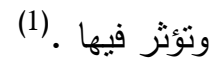
والتراث الفني والمعماري الإسلامي يقدم منظومة متكاملة من المفاهيم تشكل نسقاً قياسياً قادراً على اتخاذ

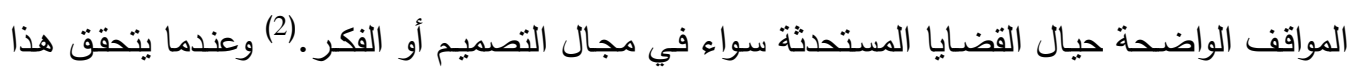
التفاعل فمردود ذلك على الإنسان حيث الارتباط بالأرض والطبيعة والتراث والتاريخ على أن الن تكون

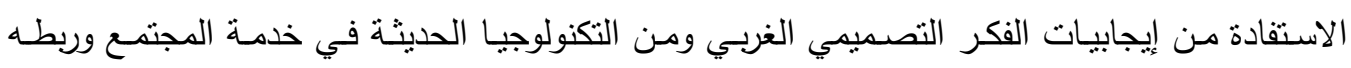
بالبيئة العربية الإسلامية. الإداتئن

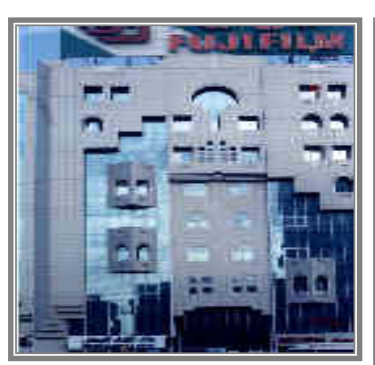

( شكل 20 (مبني إداري بدبي ) (إنبي )

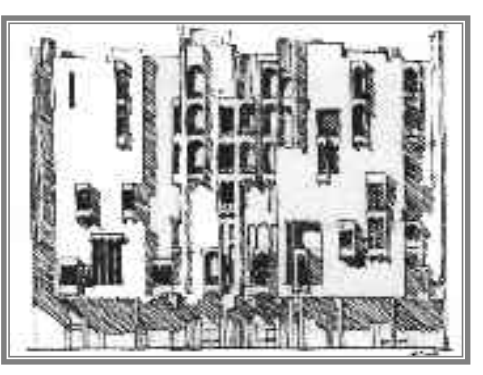

( شكل 19) ( مبني إتحاد الصناعات بيغداد)

محاولة التعبير عن القيم الحضارية الإسلامية

وقد شاهدت منطقة الخليج بعض التجارب المعمارية لكثير من المعماريين العالميين لربط العمارة الحديثة بالقيم الإسلامية .. ولكن ضعف اللقاء الفكري بين المعماريين المسلمين باعد بين المفاهيم المشتركة

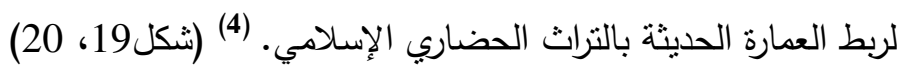

$$
\begin{aligned}
& \text { 5- تجريتا منظمة المدن العربية والأغا خان للعمارة: }
\end{aligned}
$$

العمل التصميمي ينشـأ من الظروف البيئية ومن الإمكانات المتوفرة واحتباجـات العصدر ليكون حلوناً

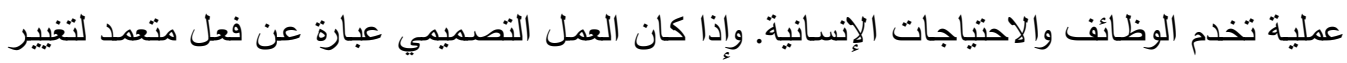

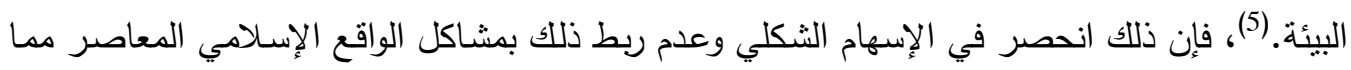

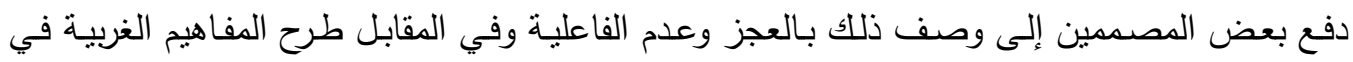

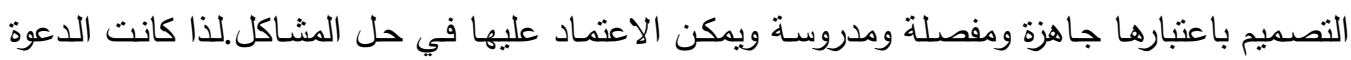
والاستجابة للعوامل الطارئة الجديدة من خلال قانون النمو والتجارب والتغير مع ظروف الحئه الحياة .بالإضافة

(1)Monro,T., The Psychology of Art,Past,Present, Future, in Psychology and Visual Arts,

London, Penguin Book,1969, p. 12

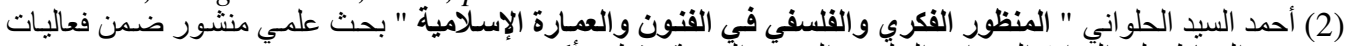

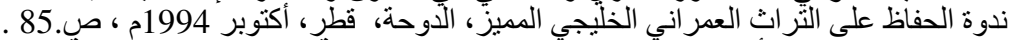

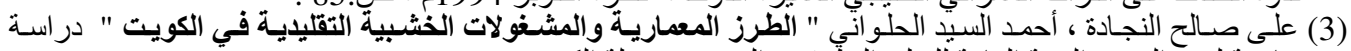

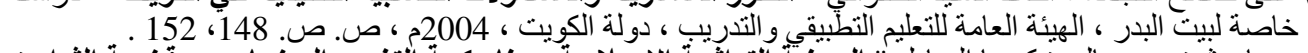

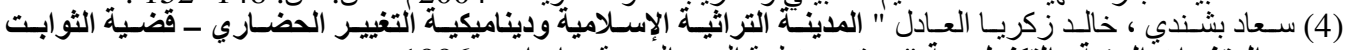

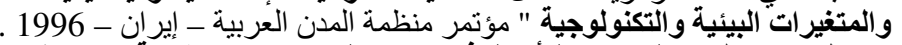

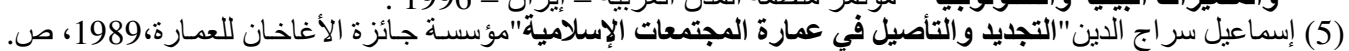


إلى أن هناك نمـاذج ومحساولات تصميمية جادة تمثنل مرحلـة من التحول والتجريب والبحث المستمر تسنوفى معايير الاستجابة الإبداعية للبعد التاريخي والاجتماعي للبيئة، والتأكيد على الانتماء والأصالة.. وتكوين رمزية بيئية جديدة.

وتعد تجربـة منظمـة المدن العربيـة وكذللك تجربـة الأغاخـان للعمـارة مرتعـاً خصباً للإحيـاء والاستجابة وترجمة صادقة في التجديد والتأصيل، وتتمثل أهداف كل من التجربتين في الآتي:

\section{The Arab Towns Organization (") 1/5 منظمة المدن العربية وتهدف إلى تحقيق ما يلي ("*)}

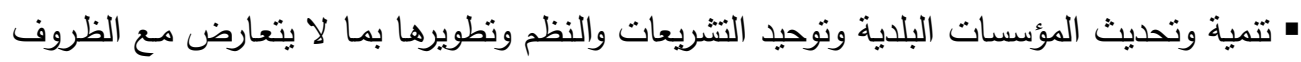
المحلية.

• الحفاظ على هوية المدينة العربية وتراثها. • رفع الخدمات والمرافق البلدية. • معاونة البلديات على تحقيق مشاريعها الإنمائية. 1/1/5 جائزة منظمة المدن العربية.. تتألف من: 1/1/1/5

• المشروع المعماري: يخصص لأفضل مشروع معماري نفذ في مدينة عربية. • التراث المعماري: وذلك بمواصلة أعمال الترميم وإعادة نوظيف المعالم والمباني والحفاظ والإحياء لجزء مهم من المدن التاريخية.

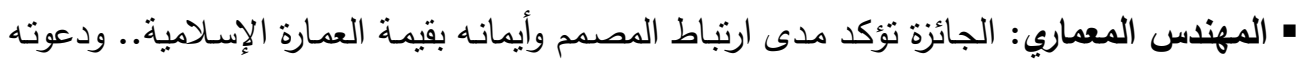
لها في أعماله التصميمية.

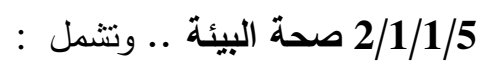

• الوعي البيئي: مدينة عربية تختص بأعمال التوعية والإرشاد البيئي.

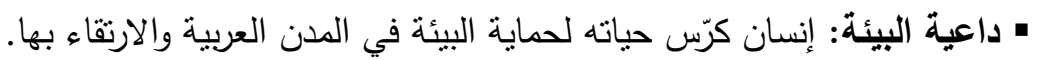

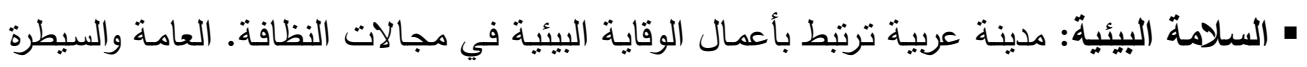
على الضجيج والملوثات. 3/1/1/5 التشجير وتجميل المدن.. ويشمل:

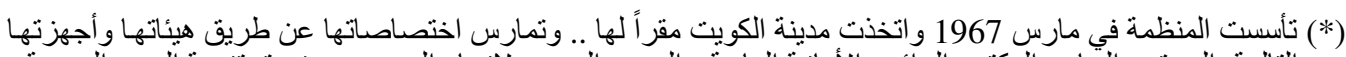

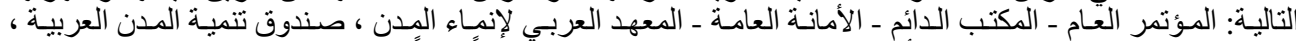

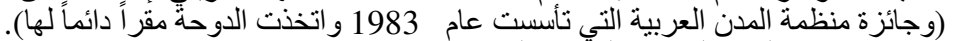
(**) جائزة منظمة المدن العربية: الجؤئز المعمارية ( وثائق ومنجز وات) ص 94. 
• تخضير المدينـة: مدينـة عربيـة تقوم بأعمال توسيع وصيانة الرقعة الخضـراء للمدينـة واستحداث نباتات ملائمة للبيئة المحلية وإظهار البعد الفني والجمالي للحدائق.

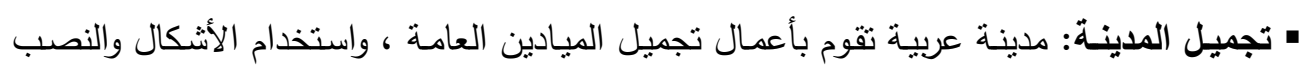

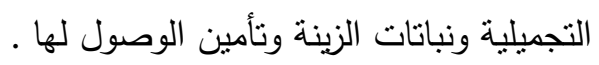
• خبير تجميل المدن: مصمم أو فنان له بصمته في تجميل المدن والالتزام بالقيم التراثية الإسلامية.

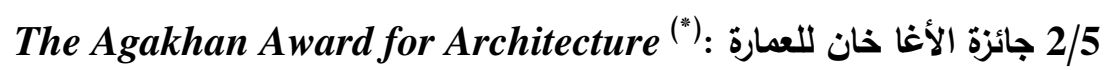
تعتبر هذه التجربـة أيضـاً .. ترجمـة صـادقة في التجديد والتأصيل (1) وأداة لإثراء الحـوار بين

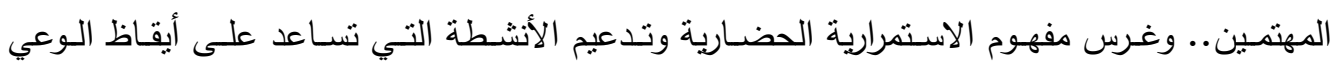

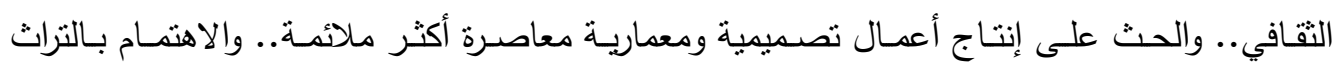

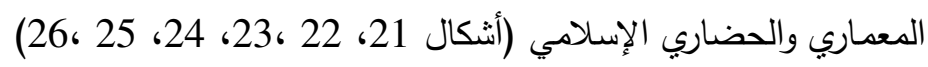

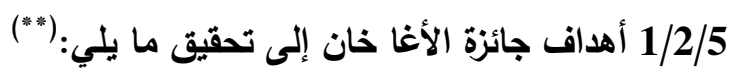

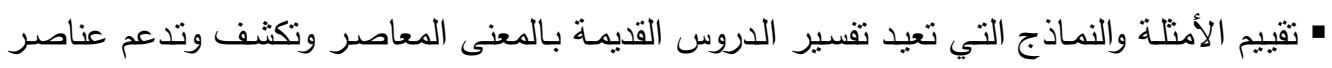
الاستمرارية الثقافية في بيئة معينة.

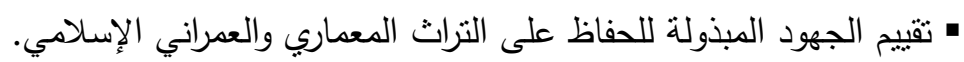
• التعرف على الجهود المبتكرة في اتجاهاتها لمعالجة المشاكل الخاصة في بيئاتها المحلية. • شمول المباني التي أقيمت بواسطة غير المعماريين.

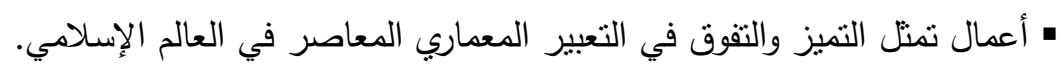

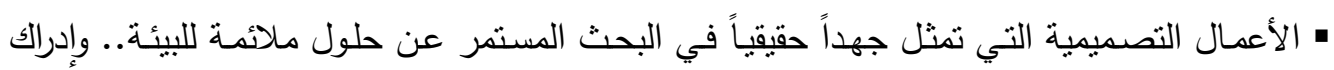
الأبعاد الاجتماعية والتاريخية.
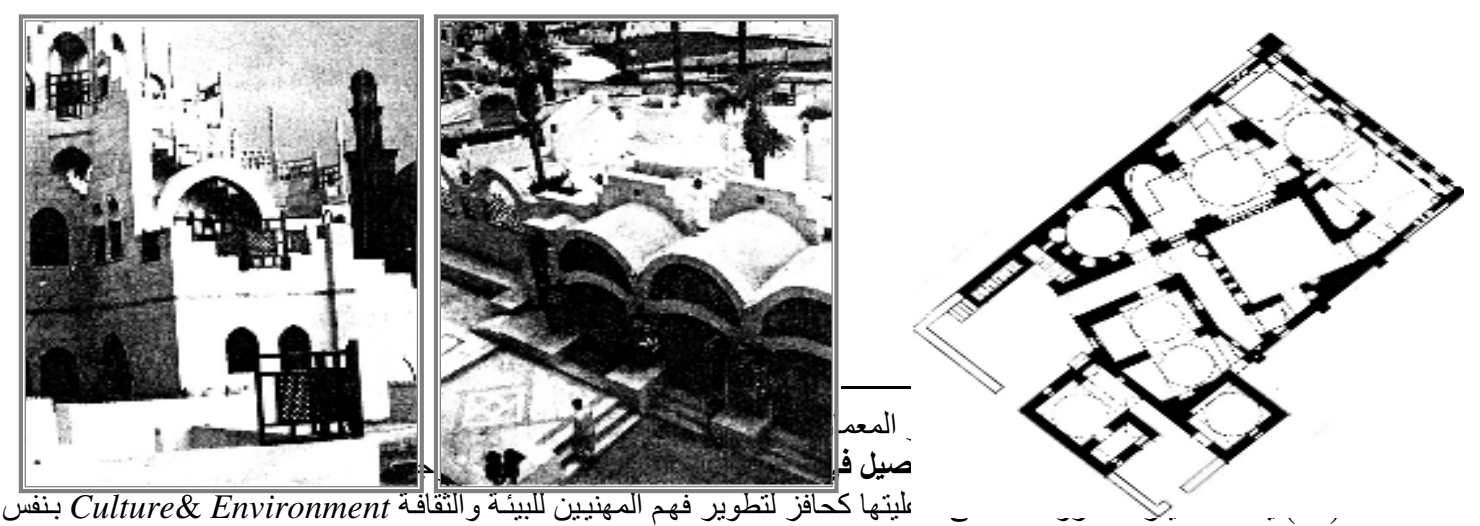

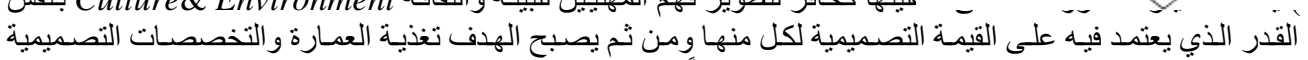

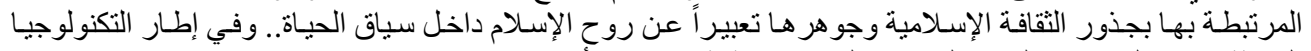
الحديثة..، هذا إلى جانب البحث الفكري و الذي يعد بمثابة الإسهام الأكبر. 
(شكل 21) رمسيس ويصا واصف("* ") مركز الفنون بالجيزة، يعبر عن التجانس ( شكل 22) د. عبد الحليم إبراهيم - الحديقة النقافية - أظهر

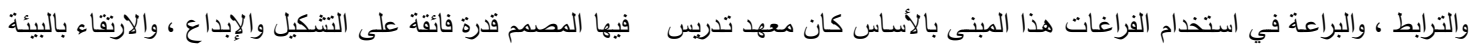

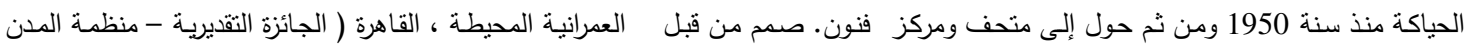
المعماري رمسيس احد تلامذة أبو المعماريين المرحوم حسن فتحي والعشق الأزلي العربية 90 - 1950). للطين .(جائزة أغاخان 1983 )
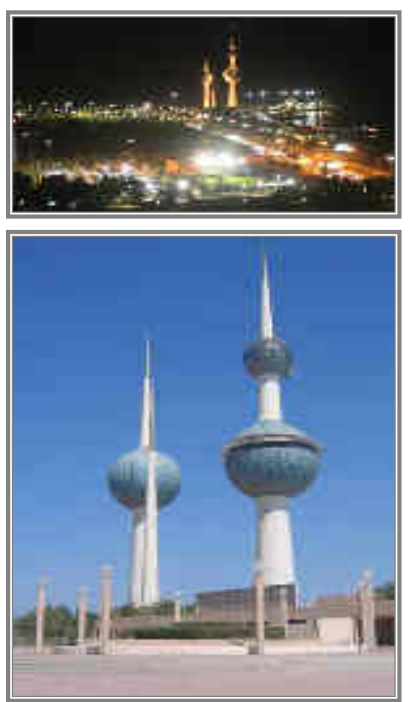

اعتبرت رمزا لدولة الكويت(") (فائز بجائز الأغا خان للعمارة(1980)

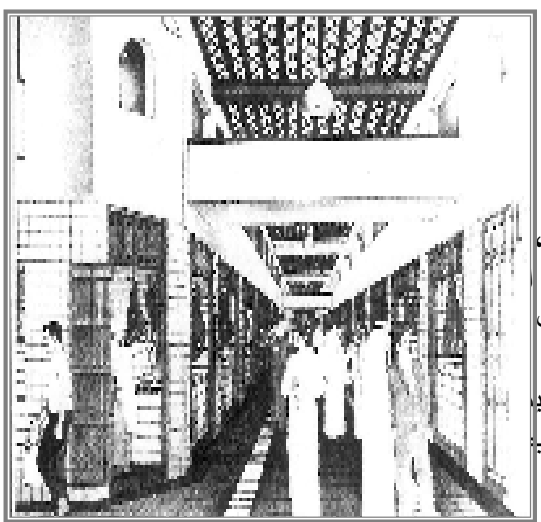

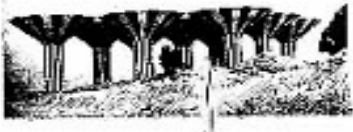

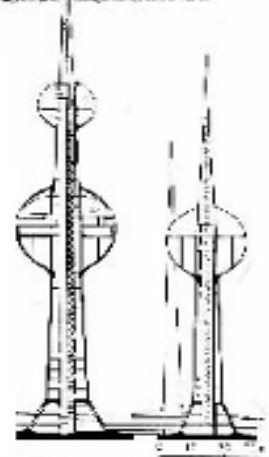

(شكل 23) أبر اج الكويت

تصميم لندستروم وشركاه

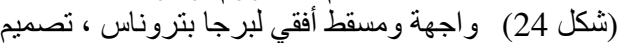

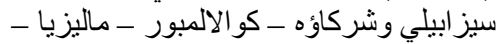

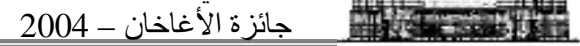
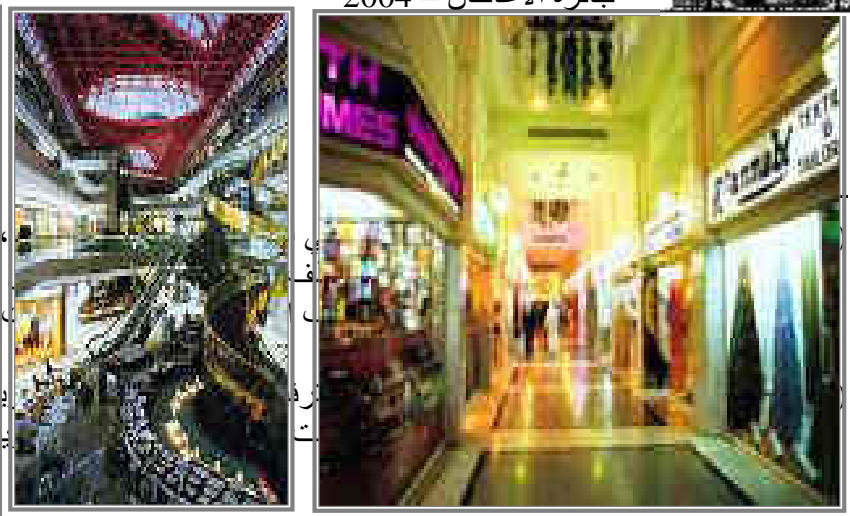

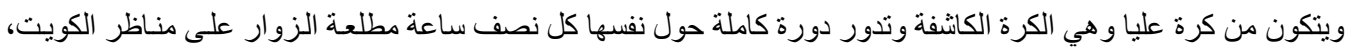

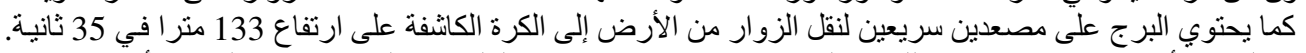

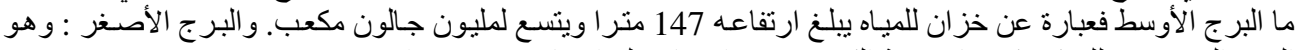
(1) www.moi.gov.kw

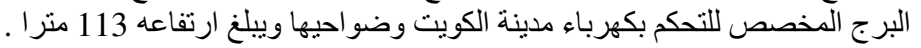


( شكل25) سوق الديرة بالكويت (1) بعبر عن التكامل من خلال إيجاد بيئة تسوق ملائمة وجذابة مع الحفاظ على الاستمرارية

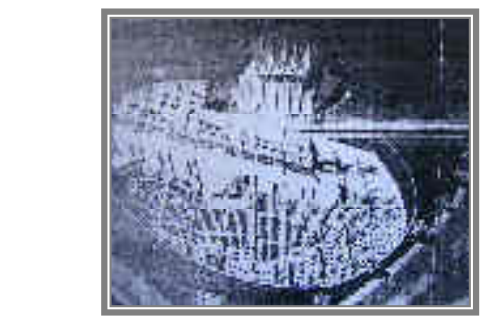
الحضارية- 1996

نموذج مصغر للمكتبة موضحاً زاوية الميل ras

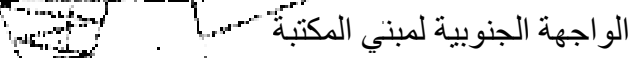

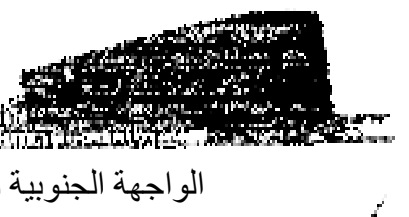

الو اجهة الثُمبالية لمبني المكتبة

(شكل 26) مسقط أفقي وقطاع طولي ، مكتبة الإسكندرية

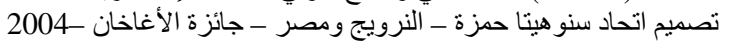

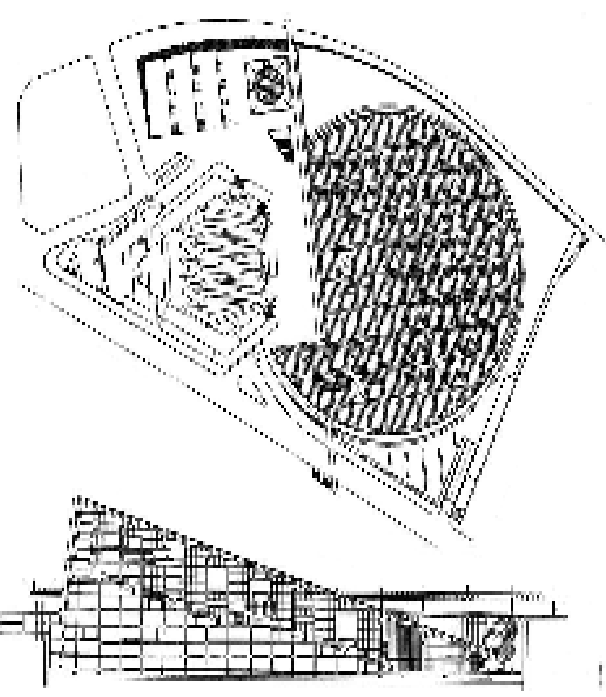

\section{Results \& Recommendations النتائج والتوصيات}

بعد استعراض البحث ومضمونه الذي يحمل بين طياته أثر البيئة على التصميم، رأينا كيف أثرت البيئة على شكل ووظيفـة المبـاني داخلياً وخارجياً على مـر العصـور ، وكيف اسـتفاد بها الأوائل وطوعوهـا لخدمتهم.. وخاصـة المصـمم المسـلم ، ووجدنا أنـهـ في الوقت الحاضـر وفي ركب المعاصـرة أن أثر التصميم على البيئة هو الأكثر تأثيراً.. وقد يكون أشد خطراً على راحة الإنسان وسلوكه الحضاري. وبالنسبة لمجتمعنا العربي والإسلامي.. فإن التطورات الجديدة والتغيرات الحادثة فيه قد دفعت بـه إلى نوع من الحياة.. نشأ عنها تطلعات جديدة أكثر تقدماً وتطوراً. وإذا كان قد حدث هذا التغيير في البنـاء والشكل والرؤيـة البصـرية، إلا أنتا يجب علينـا عدم إغفال التجـارب التصـيمية سـالفة الذكر وترجمتهـا الصـادقة والمتميزة في التجديـ والتأصسيل وتجميـل المـدن والالتزام بالقيم التراثية، والأبعاد التاريخية والاجتماعية للبيئة العربية الإسلامية، بالإضافة إلى أن المجتمع 
على وعي وبصيرة بتراثه الإسلامي Islamic Heritage وأمور دينه وأساسه الأخلاقي يكفل له التصدي لأي فكر يخالف عقيدته. .وبيئته. وقتاعتتا الآن تتمثل في التأكيد على المعايير الجادة لكـلاً من جائزة منظمـة المدن العربيـة.. وجائزة

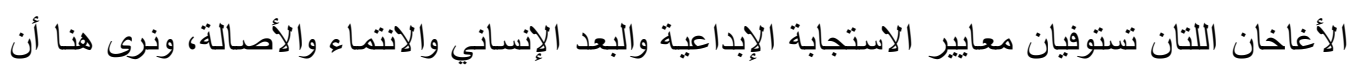

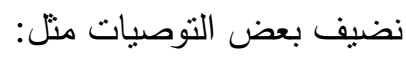
• إعادة تعريف مفهوم التصميم وتطبيقه وفق الروئية البيئية والإسلامية.

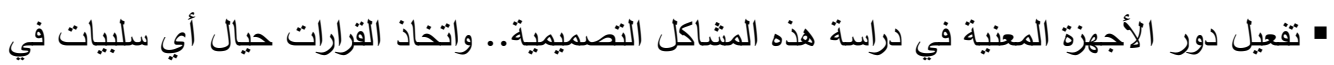
التصميم والتنفيذ. • وضع معايير لتقييم الأعمال التصميمية. • الاستفادة من التقدم العلمي والتكنولوجي ومن الأساليب الحديثة في التشيبد، وبناء المباني الذكية ومواكبة النطور في تكنولوجيا النانو Nano Technology بrt Buildings العربية والإسلامية. - الدعم الحكومي والمؤسسي للتخصصات المرتبطة بالفنون والعمارة وتجميل المدن، ونخص بالاهنمام

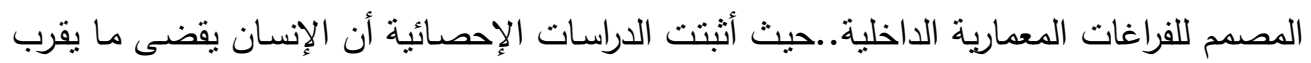
من 90\% من وقته وحياته داخل الفراغ المعماري..وهذا يؤكد أهمية المصمم الداخلي. • الاهتمام بمناهج التعليم وأساليب التربية.. وكيفية إعداد النشء للقراءة البصاء التربية الصحيحة.

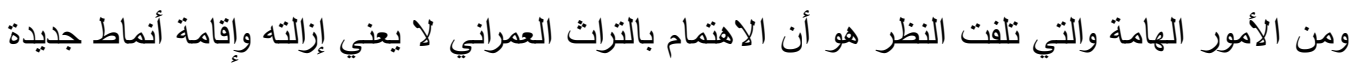

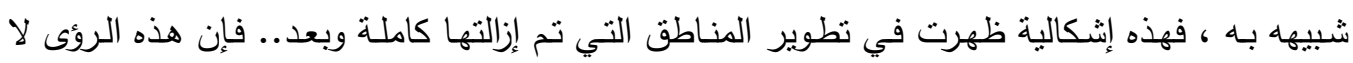

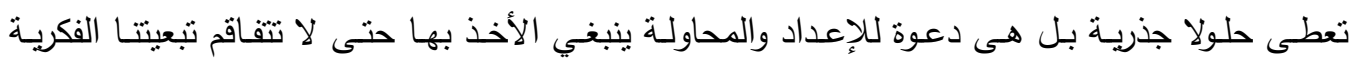

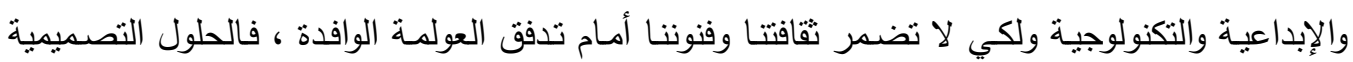
يجب أن لا تخضـع لتطور التقنيات وعلوم البناء فحسب بل تمتـ للبحث في القيم الوجدانية الإيمانية

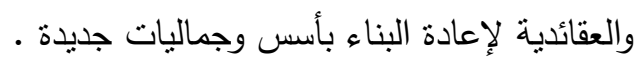
النقطة الأخيرة هنـا ، هي مـا يجب على المصدم عمله ، هل سيكون عليه أن يعيد النظر فيما تم تصميمه أو ماذا بفعل ؟ لتجنب هذا الأمر وللإجابة على هذا التساؤل ، فعلي المصمم أن يدرس الأنماط المستقبلية لتتيح له اله

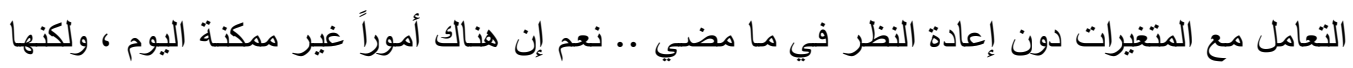

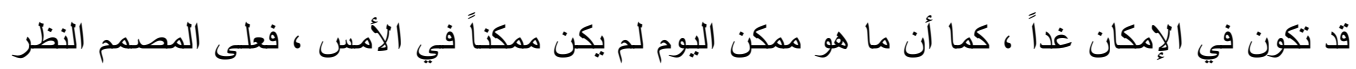

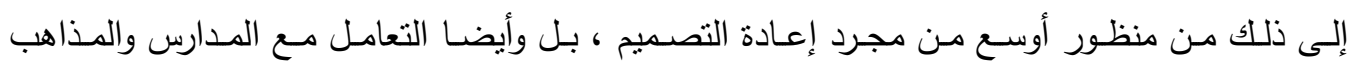

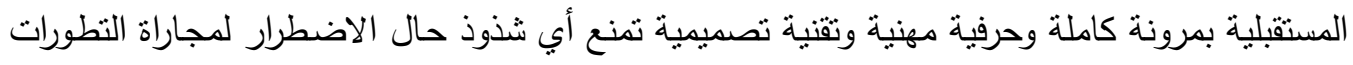


المستقبلية ، مع أهية الاحتفاظ بالمكتسبات الحالية ، والتي ستكون نتاج أكثر من قرن من الزمن من

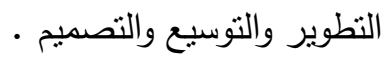

\section{المراجع}

أولاً: المراجع العربية :

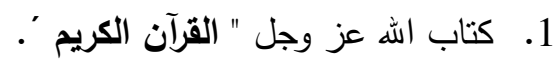

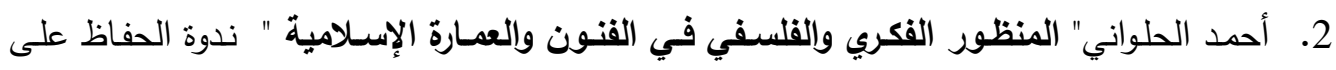

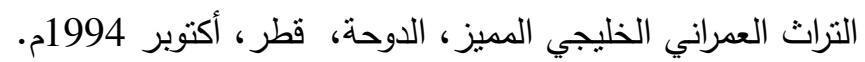

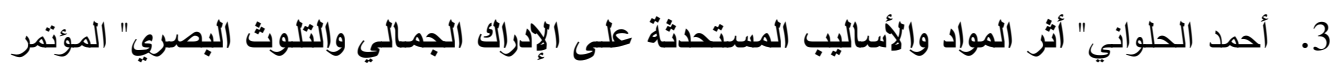

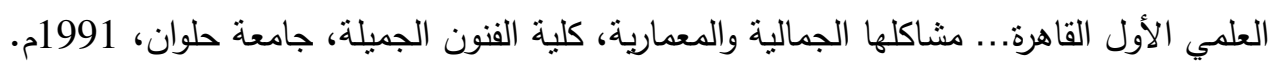
4. إسماعيل سـراج الدين " التجديـ وإلتأصسيل في عمـارة المجتمعـات الإســلامية " ، تجربـة جائزة

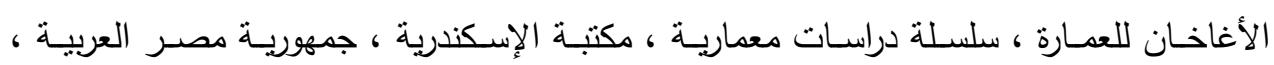
- 2007

5. إسماعيل طه نجم " الفنون التثكيلية وأثرها على الحياة اليومية " بحث منشور ، المؤتمر العلمي

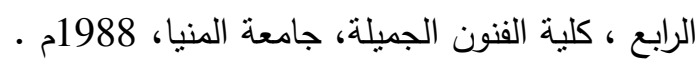

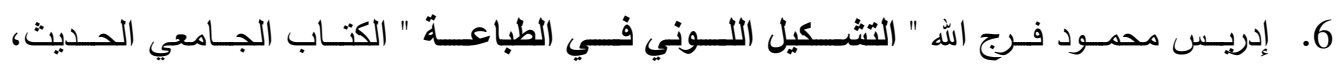
الإسكندرية،1976.

7. جون ديوى " الفن خبره " ترجمة : زكريا إبراهيم ، دار النهضة العربية ، القاهرة ، 1962م .

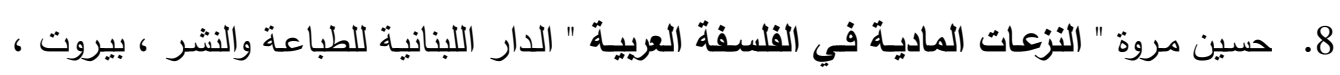
1982م،

9. حسن فتحي " العمارة والبيئة "، مجموعة كتابك، العدد 17، دار المعارف، القاهرة، 1997م .

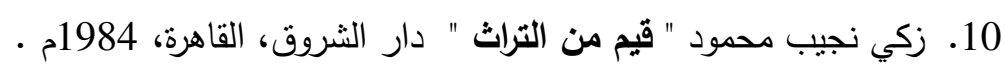

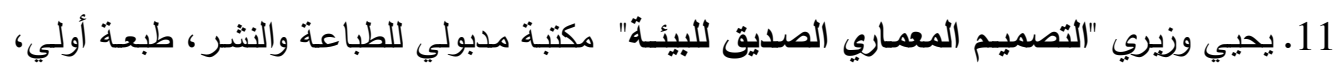

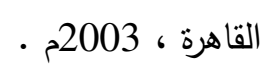

12. روبرت جيلام سكوت"أسس التصميم"تزجمة: محمد يوسف،عبد الباقي إبراهيم،دارالنهضة،القاهرة، .1968

13. سعاد بشندي ، خالد زكريـا العادل" المدينـة التراثيـة الإسـلامية وديناميكيـة التغيير الحضـاري ـ قضية الثوابت والمتغيرات البيئية والتكنولوجية " مؤنمر منظمة المدن العربية - إيران - 1996 ـ

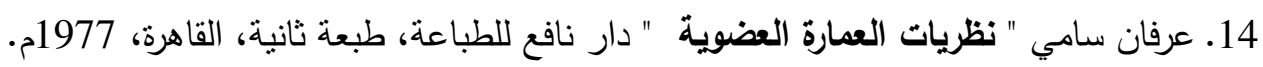


15. عرفان سامي" نظريات العمارة " مؤسسة طباعة الألوان المتميزة ، طبعة خاصة، القاهرة ، 1966م. 16. عبد الباقي إبراهيم"المنظور الإسـلاهي للنظريـة المعماريـة"مركز الدراسـات التخطيطية والمعمارية،

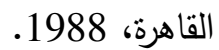

17. على صالح النجادة ،أحمد الحلواني" الطرز المعمارية والمشغولات الخشبية التقليدية في الكويت "

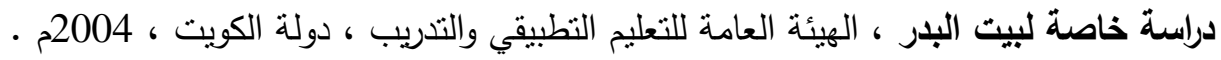

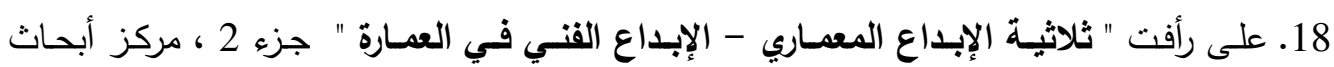

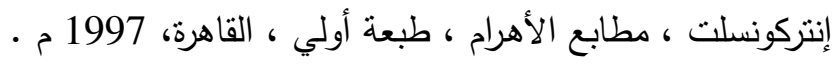

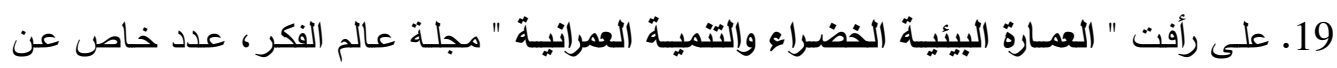

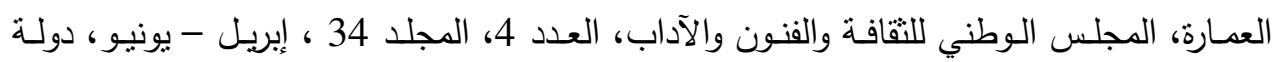
الكويت، 2006م.

20. غوستاف لوبون" حضارة العرب" ترجمة : عادل زعيتر، دار إحباء الكتب العربية، القاهرة،1976.

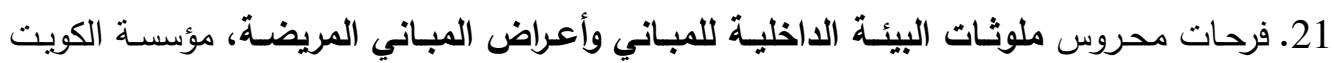

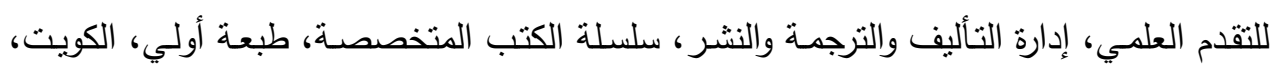
.2001

22. محمد عبد القادر الفقي" البيئة، مشـاكلها وقضـاياها وحمايتها مـن التلـوث " مكتبـة أبن سينا، القاهرة، 1993.

23. محمد محمود عويضـة " تطور الفكر المعـاري في القرن العشرين " دار المعـارف، القاهرة ، 1984

ثانياً : المراجع العربية :

24. Anwarul Islam\& Nawal H. Al-Sanafi, The Traditional Courtyard House of Kuwait and influence of Islam, Courtyard Housing, Past, Present,and Future, Edit by Brian Edwards\& Others, Taylor and Francis Group, New York, 2006.

25. Broadbent. G; Design in Architecture, Architecture \& the Human Sciences' John Willy \& Sons, New York 1968.

26. Monro, T., The Psychology of Art,Past ,Present, Future, in Psychology and Visual Arts, London, Penguin Book,1969

27. Moffett, Marian \& Others, A World History of Architecture, Laurence King Publishing, London,2003,

28. Koji Yoji, A. Japanese Touch for your Home, Japan, 1992, p. p. 71 , 73

29. Whitehead, Randall, The Art of Outdoor Lighting, Landscapes with the Beauty of Lighting, Rockport Publishers, U.S.A, 2001. 
30. http://ar.wikipedia.org/wiki/

31. http://www.flickr.com

32. http://www.alhandasa.net/forum/showthread.

33. http://www.omranet.com/vb/showthread.php?t=27

34. http://www.archnewsnow.com/features/images/Feature0161_04x.jpg

35. http://www.arab-eng.org/vb/t19561-2.html

36. www.arab-ency.com/index.php? module $=$ pnEncyclopedia\&func

37. http://top.trytop.com/thread.html

38. $\mathrm{http}: / / \mathrm{www}$. arabbeat.com/i/6th/museum.htm 